\title{
Precipitation Reaction Mechanisms of Mineral Deposits Simulated with a Fluid Mixing Model
}

\author{
Yan Zhang $\mathbb{D}^{1}{ }^{1}$ Runsheng Han $\mathbb{D}^{1},{ }^{1}$ Xing Ding, ${ }^{2,3}$ Yurong Wang, ${ }^{2}$ and Pingtang Wei ${ }^{4}$ \\ ${ }^{1}$ Kunming University of Science and Technology, Southwest Geological Survey, Geological Survey Center for Non-ferrous \\ Mineral Resources, Kunming 650093, China \\ ${ }^{2}$ State Key Laboratory of Isotope Geochemistry, Guangzhou Institute of Geochemistry, Chinese Academy of Sciences, \\ Guangzhou 510640, China \\ ${ }^{3}$ CAS Center for Excellence in Tibetan Plateau Earth Sciences, Beijing 100101, China \\ ${ }^{4}$ Kunming Geological Prospecting Institute, China Metallurgical Geological Bureau, Kunming 650024, China
}

Correspondence should be addressed to Runsheng Han; 554670042@qq.com

Received 16 September 2020; Revised 31 December 2020; Accepted 23 January 2021; Published 22 February 2021

Academic Editor: Giovanni Mongelli

Copyright (C) 2021 Yan Zhang et al. This is an open access article distributed under the Creative Commons Attribution License, which permits unrestricted use, distribution, and reproduction in any medium, provided the original work is properly cited.

\begin{abstract}
Nonmagmatic, carbonate-hosted epigenetic hydrothermal $\mathrm{Pb}-\mathrm{Zn}$ deposits similar to those at the Huize $\mathrm{Pb}-\mathrm{Zn} \mathrm{Mine}$ are widespread across the Sichuan-Yunnan-Guizhou (SYG) polymetallic province. The precipitation mechanisms of these geologically intriguing deposits are an area of interest for many researchers. To simulate the underlying precipitation reaction mechanisms and dynamics of each aspect, a fluid mixing model for metal sulfide precipitation was used in a series of experiments, where solutions that contain $\mathrm{Pb} / \mathrm{Zn}$ chloride complexes and sulfide were subjected to $\mathrm{pH}$ changes, water-rock reactions, and dilutions. Based on the results of these experiments, thermodynamic phase diagrams, and other experimental findings, a fluid mixing genetic model was developed for SYG $\mathrm{Pb}-\mathrm{Zn}$ deposits, and this model was used to analyze the mechanisms of metal sulfide precipitation. The results indicate that acidic fluids in the form of chloride complexes transported $\mathrm{Pb}$ and $\mathrm{Zn}$, whereas sulfide exists in the form of $\mathrm{H}_{2} \mathrm{~S}$ within these fluids. The precipitation of metal sulfides occurs when these fluids undergo changes in $\mathrm{pH}$, water-rock reactions, or isothermal dilution. The $\mathrm{pH}$ changes were found to be the most effective method for the induction of sulfide precipitation, followed by dilution and then water-rock reactions. The formation of sulfide precipitates due to $\mathrm{pH}$ changes, water-rock reactions, and dilution can be attributed to a single mechanism, i.e., changes in the $\mathrm{pH}$ of the fluid. Therefore, changes in $\mathrm{pH}$ are the primary mechanism of sulfide precipitation.
\end{abstract}

\section{Introduction}

Since the 1990s, there have been numerous studies on the $\mathrm{Pb}-\mathrm{Zn}$ deposits in the Sichuan-Yunnan-Guizhou (SYG) polymetallic region, which are typified by the Huize $\mathrm{Pb}-\mathrm{Zn}$ deposit. These studies have yielded several important discoveries regarding the geological background of this region and the geological features of its deposits [1-7], most notably in terms of the deposit geochemistry [4, 8-16], the structure of the ore field $[4,5,7]$, and the genesis of these deposits $[1$, $2,4,8,11,17]$. Based on the unique geological characteristics of the mineral deposits in the SYG region (i.e., the high-grade ore, the tremendous scale of their metal reserves and large size of a single orebody, the large number of associated components, the significant depth of the orebodies, the high mineralization temperature, the elevated alteration strength, and the evident mineral assemblage zoning), Han et al. [5, 18] proposed that the nonmagmatic, carbonate-hosted epigenetic hydrothermal $\mathrm{Pb}-\mathrm{Zn}$ deposits can be divided into two "end-members," i.e., Mississippi Valley-type (MVT) and Huize-type (HZT) $\mathrm{Pb}-\mathrm{Zn}$ deposits.

The mechanisms of sulfide precipitation in the Huize $\mathrm{Pb}-$ $\mathrm{Zn}$ deposit are as follows:

(1) Fluid Mixing. Based on $\mathrm{C}-\mathrm{O}$ isotopic analysis, Huang et al. [11, 19-21] concluded that fluid mixing is a critical 
process for mineralization. Luo et al. [22] proposed that fluid mixing is the main mechanism for metal precipitation; these insights were based on the findings of previous fluid inclusion studies. By analyzing Sr isotopic compositions and fluid inclusions, Zhang et al. [23-25] concluded that fluid mixing and boiling are the primary causes of sulfide precipitation.

(2) Boiling. Han et al. [5, 26, 27] proposed that decompression boiling is one of the most important mechanisms for $\mathrm{Pb} / \mathrm{Zn}$ enrichment and mineralization.

(3) pH Changes. Zhou [28], Yan [29], and Zhong et al. [30] all agree that changes in the $\mathrm{pH}$ are the primary cause of sulfide precipitation.

In summary, the mechanisms of sulfide precipitation have been investigated via fluid inclusion studies, as well as trace element and isotopic tracing methods. However, the findings of these studies have not been validated by complementary methods, such that the evolution process of the mineralization fluids has yet to be fully elucidated because of the experimental limitations of such studies. Based on the findings of previous geological studies and other research data, Zhang et al. $[15,16,31-33]$ conducted a series of fluid inclusion studies, isotopic analyses, thermodynamic analyses, and mineralization experiments at ambient temperature and pressure. Based on their observations, they concluded that fluid mixing is the primary mechanism for metal sulfide precipitation from hydrothermal fluids in the Huize $\mathrm{Pb}-\mathrm{Zn}$ deposit.

Zhang et al. [31] performed a series of mixing experiments at ambient temperature and pressure, where NaHS was titrated into metal chloride solutions (with and without dolomite rocks); they found that metal precipitation during fluid mixing depends on the stability of the metal complexes involved in this process and the $\mathrm{pH}$ of the mixing environment. The environmental $\mathrm{pH}$, in particular, is the primary determining factor for metal precipitation during fluid mixing. The aforementioned mixing process is a process that couples $\mathrm{pH}$ changes, water-rock interactions, and dilution, where the subprocesses, mechanisms, and results of this process have already been studied and discussed in significant detail $[31,32]$. However, when the $\mathrm{pH}$ changes, water-rock interactions and dilutions occur in isolation. Thus, the exact chemical reactions that lead to metal precipitation in the form of sulfide complexes have yet to be identified, and little is known about the dynamics of their chemical reactions or the factors that control the rate and occurrence of these chemical reactions. Nonetheless, with regard to the standalone effects of $\mathrm{pH}$ changes, water-rock interactions, and dilutions, we can assume that the following process occurs: when subsurface fluids migrate in massive quantities over long distances, the metal-bearing fluid extracts small amounts of sulfide throughout this process. As the fluid is acidic and the sulfide concentration is insufficient to induce precipitation, the chloride complexes of $\mathrm{Pb}$ and $\mathrm{Zn}$ are much more stable than their sulfur-hydrogen counterparts under these conditions. Therefore, $\mathrm{Pb} / \mathrm{Zn}$ and sulfides exist within the mineralization fluid as chloride complexes and $\mathrm{H}_{2} \mathrm{~S}$, respec- tively. However, if a change occurs in the physical and chemical conditions of the fluid, the $\mathrm{Pb} / \mathrm{Zn}$ chloride complexes become unstable and the $\mathrm{Pb} / \mathrm{Zn}$ elements bind to the sulfides instead, which in turn leads to their precipitation as metal sulfides. In this study, a series of geochemistry experiments were performed, where solutions that contain $\mathrm{Pb} / \mathrm{Zn}$ chloride complexes and sulfide were subjected to $\mathrm{pH}$ changes, waterrock reactions, and dilution. Based on the results of these experiments, thermodynamic phase diagrams, and other experimental data, a fluid mixing genetic model for SYG $\mathrm{Pb}-\mathrm{Zn}$ deposits was developed to elucidate the reaction mechanisms by which metal element precipitation occurs in these deposits.

\section{Materials and Methods}

2.1. Preparation of the Solutions and Specimens. Carpenter et al. [34] first measured the metal concentration of basin brines from an MVT deposit. They analyzed the oil field brines of tens of deposits from the Gulf Coast and observed $\mathrm{Pb}$ and $\mathrm{Zn}$ concentrations up to 111 and $575 \mathrm{ppm}$, respectively. In a review of sedimentary basins around the world, Yardley [35] reported observations of $\mathrm{Pb}$ and $\mathrm{Zn}$ concentrations of up to $100 \mathrm{ppm}$ and several hundred ppm in crustal fluids. A few early studies on the MVT deposits from the Cave-in-Rock district of southern Illinois also detected high metal concentrations in fluid inclusions from these deposits $[36,37]$. Czamanske et al. [36] observed Zn concentrations greater than $500 \mathrm{ppm}$ in fluorite fluid inclusions, whereas Pinckney and Haffty [37] reported $\mathrm{Zn}$ concentrations between 10 and $1040 \mathrm{ppm}$ in the fluid inclusions of various crystals. In general, the age of mineralization correlates with the metal concentration of the accompanying fluid inclusions (with higher metal concentrations in early-stage mineralization material), but these concentrations are highly variable. Stoffell et al. [38] used laser ablation inductively coupled plasma mass spectrometry (LA-ICP-MS) to analyze the metal concentrations of single fluid inclusions from MVT deposits in northern Arkansas and the Tri-State district. They found that the $\mathrm{Pb}$ and $\mathrm{Zn}$ concentrations of these fluid inclusions range between 0.7 and $95 \mathrm{ppm}$ and 0.2 and 400 ppm, respectively. The highest metal concentrations in both of these districts were found in sphalerite-hosted inclusions. The $\mathrm{Zn}$ concentrations of quartz- and calcite-hosted inclusions from these districts range from 0.1 to $34 \mathrm{ppm}$. Based on LA-ICP-MS analyses of the $\mathrm{Pb}$ concentration of fluid inclusions from the MVT deposits of northern Arkansas and the $\mathrm{Zn} / \mathrm{Pb}$ ratio of their basin brines, Wilkinson et al. [39] estimated that the $\mathrm{Zn}$ concentration of these fluid inclusions may be as high as $3000 \mathrm{ppm}$. The metal concentrations they observed in sphalerite-hosted inclusions were more than two orders of magnitude greater than those of cogenetic gangue-hosted inclusions.

In this study, $\mathrm{Pb} / \mathrm{Zn}$ solutions were prepared with a $\mathrm{Pb}$ concentration of $100 \mathrm{ppm}$ and $\mathrm{Zn}$ concentration of $500 \mathrm{ppm}$. Let $b=\omega \rho 1000 / M$, where $b$ is the molality, $\omega$ is the mass concentration, $\rho$ is the density, and $M$ is the molar mass. Inputting $\omega_{\mathrm{Pb}}=100, M_{\mathrm{Pb}}=207.2, \omega_{\mathrm{Zn}}=500, M_{\mathrm{Zn}}=$ 65.41 , and $\rho=1$ into this equation yields $b_{\mathrm{Pb}}=0.00048 \mathrm{~mol} /$ 
$\mathrm{kg}$ and $b_{\mathrm{Zn}}=0.0076 \mathrm{~mol} / \mathrm{kg}$. To simplify the calculations, the values of $b_{\mathrm{Pb}}$ and $b_{\mathrm{Zn}}$ were rounded to $0.0005 \mathrm{~mol} / \mathrm{kg}$ and $0.01 \mathrm{~mol} / \mathrm{kg}$, which correspond to the mass concentrations of 103.6 and $654.1 \mathrm{ppm}$, respectively.

High-oxidation-state metal ions, such as $\mathrm{Fe}^{3+}$ and $\mathrm{Al}^{3+}$, undergo intense hydrolysis reactions in aqueous solutions. Similarly, divalent metal ions, such as $\mathrm{Fe}^{2+}, \mathrm{Cu}^{2+}, \mathrm{Pb}^{2+}$, and $\mathrm{Zn}^{2+}$, may also be hydrolyzed to a certain extent. As the precipitation of metal sulfides is directly determined by the solution $\mathrm{pH}$, it also poses the greatest hindrance to element transport. Therefore, during the preparation of the $\mathrm{Pb} / \mathrm{Zn}$ solutions, their $\mathrm{pH}$ must be carefully controlled to prevent cationic hydrolysis (Table 1). According to Le Chatelier's principle, increasing the $\mathrm{H}^{+}$concentration (acidifying the solution) will shift the reaction equilibrium to the left (see Table 1). Hence, metal hydrolysis can be prevented by acidifying the solution.

The stability constant of metal chloride complexes is at least four orders of magnitude greater than that of metal hydroxide complexes (Table 2). Therefore, the former is much more stable than the latter. White flocculent precipitates appear immediately if a $2.5 \mathrm{~mol} / \mathrm{L} \mathrm{ZnCl}_{2}$ solution is diluted with pure water, but no precipitates form if it is diluted with $4 \mathrm{~mol} / \mathrm{L} \mathrm{NaCl}$. This is because brine addition converts $\mathrm{ZnCl}_{2}$ into a stable six-coordinate $\mathrm{Na}_{2} \mathrm{ZnCl}_{4}$ complex. Hence, the addition of excess $\mathrm{NaCl}$ ensures that the metals exist as chloride complexes.

Given that $\beta_{1}=\left[\mathrm{H}^{+}\right] /\left[\mathrm{Zn}^{2+}\right]$, the relationship between $\mathrm{pH}$ and $\log a_{\mathrm{Zn} 2+}$ may then be obtained by substituting the value of the cumulative stability constant into this equation, as shown in the $\mathrm{pH}-\log a_{\mathrm{Zn} 2+}$ diagram in Figure 1. If $\left[\mathrm{Zn}^{2+}\right]=0.01 \mathrm{~mol} / \mathrm{kg}$ and $\mathrm{pH}=6.4, \mathrm{Zn}^{2+}$ is hydrolyzed to form $\mathrm{Zn}(\mathrm{OH})_{2}$ precipitates (white flocculent particles). As the $\mathrm{NaCl}$ solution has a $\mathrm{pH}$ of 7 , a suitable amount of acid must be added to the $\mathrm{Zn}$ solution during its preparation to prevent cationic hydrolysis.

The water-rock interaction and dilution experiments were performed using the most common type of ore-bearing host rock in the $\mathrm{HZT} \mathrm{Pb}-\mathrm{Zn}$ deposits, i.e., dolomite. The dolomite samples were obtained from the Huize deposit in Yunnan, and these samples were crushed to a 40-mesh size before use. below:

Subsequently, the solutions were prepared as described

(1) $\mathrm{Pb} / \mathrm{Zn}$ Solution without Sulfides (Mixed Solution (1)). $29.22,0.0277$, and $0.0508 \mathrm{~g}$ of analytical grade $\mathrm{NaCl}, \mathrm{CaCl}_{2}$, and $\mathrm{MgCl}_{2}$, respectively, were weighed and added to a beaker that was cleaned with deionized water. Approximately $100 \mathrm{~mL}$ of deionized water was added to the beaker, and the contents were then stirred with a glass stirring rod to dissolve the salts. Next, $0.3408 \mathrm{~g}$ of $\mathrm{ZnCl}_{2}$ and $0.0348 \mathrm{~g}$ of $\mathrm{PbCl}_{2}$ were added to the salt solution. To prevent $\mathrm{Pb}$ and Zn hydrolysis, a few drops of hydrochloric acid were added to the solution to reduce its $\mathrm{pH}$ to $<4$. The solution was then transferred to a $250 \mathrm{~mL}$ volumetric flask. Deionized water was used to wash the previously used beaker and stirring rod, and the wash was transferred to the volumetric flask. The solution was then brought up to $250 \mathrm{~mL}$ in the volumetric flask and shaken thoroughly. In this solution,
$b_{\mathrm{PbCl} 2}=0.0005 \mathrm{~mol} / \mathrm{kg}, \quad b_{\mathrm{ZnCl} 2}=0.01 \mathrm{~mol} / \mathrm{kg}, \quad b_{\mathrm{NaCl}}=2 \mathrm{~mol} /$ $\mathrm{kg}, b_{\mathrm{CaCl} 2}=0.002 \mathrm{~mol} / \mathrm{kg}$, and $b_{\mathrm{MgCl} 2}=0.002 \mathrm{~mol} / \mathrm{kg}$.

(2) $\mathrm{Pb} / \mathrm{Zn}$ Solution with Sulfides (Mixed Solution (2)). 29.22, 0.0277 , and $0.0508 \mathrm{~g}$ of analytical grade $\mathrm{NaCl}, \mathrm{CaCl}_{2}$, and $\mathrm{MgCl}_{2}$, respectively, were added to a beaker that was previously washed with deionized water, followed by the addition of approximately $100 \mathrm{~mL}$ of deionized water. The solution was stirred thoroughly using a stirring rod. Then, $0.3408 \mathrm{~g}$ of $\mathrm{ZnCl}_{2}$ and $0.0348 \mathrm{~g}$ of $\mathrm{PbCl}_{2}$ were added to the salt solution. To prevent $\mathrm{Pb}$ and $\mathrm{Zn}$ hydrolysis, a few drops of $\mathrm{HCl}$ were added to reduce the solution $\mathrm{pH}$ to $<2$. This also ensured that precipitation would not occur during NaHS titration. A total of $25 \mathrm{~mL}$ of $0.001 \mathrm{~mol} / \mathrm{kg} \mathrm{NaHS}$ was added to another beaker, and this solution was diluted to $100 \mathrm{~mL}$. A pipette was used to titrate NaHS into the previously prepared $\mathrm{Pb} / \mathrm{Zn}$ salt solution while it was stirred continuously. After the addition of NaHS, the solution was transferred to a $250 \mathrm{~mL}$ volumetric flask. Deionized water was used to wash the previously used beaker and glass rod, and the wash was then transferred to the volumetric flask. Finally, the solution was brought up to $250 \mathrm{~mL}$ in the volumetric flask and shaken thoroughly. In this solution, $b_{\mathrm{PbCl} 2}=0.0005 \mathrm{~mol} / \mathrm{kg}, b_{\mathrm{ZnCl} 2}=$ $0.01 \mathrm{~mol} / \mathrm{kg}, b_{\mathrm{NaCl}}=2 \mathrm{~mol} / \mathrm{kg}, b_{\mathrm{CaCl} 2}=0.002 \mathrm{~mol} / \mathrm{kg}, b_{\mathrm{MgCl} 2}$ $=0.002 \mathrm{~mol} / \mathrm{kg}$, and $b_{\mathrm{NaHS}}=0.0001 \mathrm{~mol} / \mathrm{kg}$.

Before preparing mixed solution (2), experiments were carried out to ensure that no precipitates, even in minuscule amounts, would occur when the $\mathrm{pH}$ was less than 2 . The specific process was as follows. To prevent $\mathrm{Pb}$ and $\mathrm{Zn}$ hydrolysis, a few drops of $\mathrm{HCl}$ were added to change the solution $\mathrm{pH}$, and a $\mathrm{pH}$ meter was used to measure the $\mathrm{pH}$. A pipette was used to titrate $\mathrm{NaHS}$ into the previously prepared $\mathrm{Pb} / \mathrm{Zn}$ salt solution while it was stirred continuously. Finally, water was added for a final solution volume of $250 \mathrm{~mL}$ in the volumetric flask. These solutions were sent to the ALS Laboratory Group for measurements of the $\mathrm{Pb}$ and $\mathrm{Zn}$ concentrations. The test results showed that when the $\mathrm{pH}$ was less than $2, \omega_{\mathrm{Pb}}=$ $104-110 \mathrm{ppm}$ and $\omega_{\mathrm{Zn}}=665-675 \mathrm{ppm}$, which were within the allowable error range of the calculated value (103.6 and $654.1 \mathrm{ppm})$. When the $\mathrm{pH}$ value was higher than 3 , the measured value was clearly lower than the calculated value, which indicates that precipitates were produced during the preparation process of the solution. Therefore, it was concluded that when the $\mathrm{pH}$ is less than 2 , the addition of the NaHS solution does not lead to the production of precipitates.

All of the reagents used in the preparation process were of analytical grade, and all of the water used in this experiment was ultrapure deionized water.

2.2. Experimental Schemes and Methods. The following processes were simulated in this study: simple $\mathrm{pH}$ changes, water-rock reactions, and isothermal dilution (simple dilution, dilution after short-lived water-rock interactions, and dilution after extensive water-rock interactions). These simulations are described in detail below:

(1) pH Changes. $20 \mathrm{~mL}$ of mixed solution (2) was poured into a small plastic bottle, and $\mathrm{HCl}$ and $\mathrm{NaOH}$ were used to adjust 
TABLE 1: Main chemical reactions of $\mathrm{Pb}$ and $\mathrm{Zn}$ in the $\mathrm{NaCl}$ solution.

\begin{tabular}{|c|c|c|c|}
\hline No. & Reaction equation & No. & Reaction equation \\
\hline$\overline{1}$ & $\mathrm{Zn}^{2+}+\mathrm{H}_{2} \mathrm{O} \leftrightharpoons \mathrm{ZnOH}^{+}+\mathrm{H}^{+}$ & 11 & $\mathrm{~Pb}^{2+}+\mathrm{H}_{2} \mathrm{O} \leftrightharpoons \mathrm{PbOH}^{+}+\mathrm{H}^{+}$ \\
\hline 2 & $\mathrm{Zn}^{2+}+2 \mathrm{H}_{2} \mathrm{O} \leftrightharpoons \mathrm{Zn}(\mathrm{OH})_{2} \downarrow+2 \mathrm{H}^{+}$ & 12 & $\mathrm{~Pb}^{2+}+2 \mathrm{H}_{2} \mathrm{O} \leftrightharpoons \mathrm{Pb}(\mathrm{OH})_{2} \downarrow+2 \mathrm{H}^{+}$ \\
\hline 3 & $\mathrm{Zn}^{2+}+3 \mathrm{H}_{2} \mathrm{O} \leftrightharpoons \mathrm{Zn}(\mathrm{OH})_{3}^{-}+3 \mathrm{H}^{+}$ & 13 & $\mathrm{~Pb}^{2+}+3 \mathrm{H}_{2} \mathrm{O} \leftrightharpoons \mathrm{Pb}(\mathrm{OH})_{3}^{-}+3 \mathrm{H}^{+}$ \\
\hline 4 & $\mathrm{Zn}^{2+}+4 \mathrm{H}_{2} \mathrm{O} \leftrightharpoons \mathrm{Zn}(\mathrm{OH})_{4}{ }^{2-}+4 \mathrm{H}^{+}$ & 14 & $\mathrm{PbCl}_{2}+2 \mathrm{NaCl}=\mathrm{Na}_{2} \mathrm{PbCl}^{3+}+3 \mathrm{Cl}^{-}$ \\
\hline 5 & $\mathrm{ZnCl}_{2}+2 \mathrm{NaCl}=\mathrm{Na}_{2} \mathrm{ZnCl}^{3+}+3 \mathrm{Cl}^{-}$ & 15 & $\mathrm{PbCl}_{2}+2 \mathrm{NaCl}=\mathrm{Na}_{2} \mathrm{PbCl}_{2}{ }^{2+}+2 \mathrm{Cl}^{-}$ \\
\hline 6 & $\mathrm{ZnCl}_{2}+2 \mathrm{NaCl}=\mathrm{Na}_{2} \mathrm{ZnCl}_{2}{ }^{2+}+2 \mathrm{Cl}^{-}$ & 16 & $\mathrm{PbCl}_{2}+2 \mathrm{NaCl}=\mathrm{Na}_{2} \mathrm{PbCl}_{3}^{+}+\mathrm{Cl}^{-}$ \\
\hline 7 & $\mathrm{ZnCl}_{2}+2 \mathrm{NaCl}=\mathrm{Na}_{2} \mathrm{ZnCl}_{3}^{+}+\mathrm{Cl}^{-}$ & 17 & $\mathrm{PbCl}_{2}+2 \mathrm{NaCl}=\mathrm{Na}_{2} \mathrm{PbCl}_{4}$ \\
\hline 8 & $\mathrm{ZnCl}_{2}+2 \mathrm{NaCl}=\mathrm{Na}_{2} \mathrm{ZnCl}_{4}$ & 18 & \\
\hline
\end{tabular}

TABLE 2: Stability constants of metal inorganic complexes $\left(25^{\circ} \mathrm{C}\right)$.

\begin{tabular}{lccc}
\hline Ligands & Metal ion & $\begin{array}{c}\text { Number of } \\
\text { ligands }(n)\end{array}$ & $\lg \beta_{n}$ \\
\hline $\mathrm{Cl}^{-}$ & $\mathrm{Pb}^{2+}$ & $1,2,3$ & $1.42,2.23,3.23$ \\
& $\mathrm{Zn}^{2+}$ & $1,2,3,4$ & $0.43,0.61,0.53,0.20$ \\
$\mathrm{OH}^{-}$ & $\mathrm{Pb}^{2+}$ & $1,2,3$ & $7.82,10.85,14.58$ \\
& $\mathrm{Zn}^{2+}$ & $1,2,3,4$ & $4.40,11.30,14.14,17.66$ \\
\hline
\end{tabular}

$\beta_{n}$ is the cumulative stability constant.

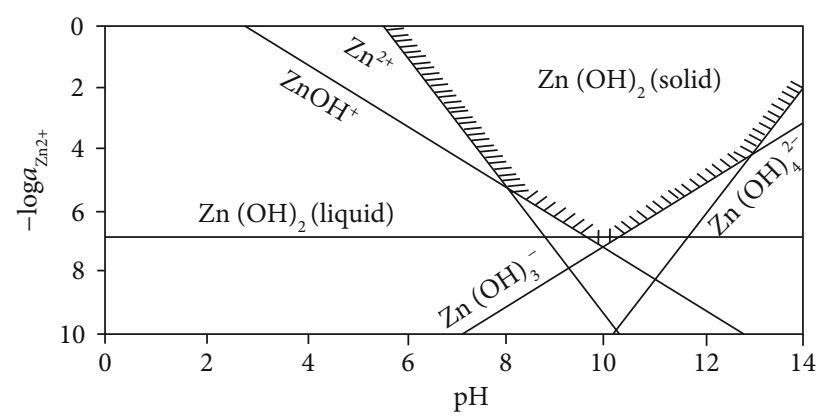

Figure 1: $\mathrm{pH}-\log a_{\mathrm{Zn} 2+}$ diagram.

these solutions to different levels of acidity. The $\mathrm{pH}$ value of the prepared mixed solution (2) was 1.81, and the experimental $\mathrm{pH}$ ranged from 1 to 10 , for which $0.3 \mathrm{~mol} / \mathrm{L} \mathrm{HCl}$ was added when necessary to obtain the experimental solution with a $\mathrm{pH}$ of 1 . To ensure the addition of the least amount of $\mathrm{NaOH}$ as possible, a series of different concentrations of $\mathrm{NaOH}(\mathrm{CNaOH}=0.0000001-0.1 \mathrm{~mol} / \mathrm{L})$ were used. After $\mathrm{pH}$ adjustment, the mixture was centrifuged and filtered. The supernatant was sent to the ALS Laboratory Group for measurements of the $\mathrm{Pb}$ and $\mathrm{Zn}$ concentrations via ICP-MS analyses, and the control was a sample whose acidity was not adjusted.

(2) Water-Rock Reactions. Water-rock reactions were simulated by observing the reaction between mixed solution (2) (a metal chloride complex system with a set quantity of NaHS) and dolomite at varying temperatures $(25,50,75$,
100 , and $150^{\circ} \mathrm{C}$ ). Mixed solution (1) was used as the control for this experiment. The water-rock interaction experiments performed by Zhang et al. [32] using mixed solution (1) indicated that the water-rock reactions reach equilibrium after $48 \mathrm{~h}$. Hence, all of the water-rock reaction experiments in this study were performed with a reaction time of $48 \mathrm{~h}$. With regard to the experimental method, $10 \mathrm{~mL}$ of mixed solution (2) or (1) was decanted into a $20 \mathrm{~mL}$ sealed centrifuge tube (or a polytetrafluoroethylene- (PTFE-) lined Morey vessel) to which $0.5 \mathrm{~g}$ of 40 -mesh dolomite was added. The mixture was then placed in a thermostatic bath $\left(50\right.$ and $\left.75^{\circ} \mathrm{C}\right)$ or muffler furnace $\left(100\right.$ and $\left.150^{\circ} \mathrm{C}\right)$. After the mixture was allowed to react for two days, it was removed from the reaction vessel and then centrifuged and filtered. The supernatant was sent to the ALS Laboratory Group for measurements of the $\mathrm{Pb}$ and $\mathrm{Zn}$ concentrations. The $25^{\circ} \mathrm{C}$ experiment was performed at ambient temperature, while the 50 and $75^{\circ} \mathrm{C}$ experiments were performed in a thermostatic bath. The 100 and $150^{\circ} \mathrm{C}$ experiments were performed in a muffler furnace using the PTFE-lined Morey vessel as the reaction vessel.

(3) Isothermal Dilution. In the natural world, tectonic stress fields often transport fluids with varying compositions, properties, and temperatures/pressures into the same space, where dilution is ever-present throughout this process. Dilution processes may be either isothermal or nonisothermal, depending on the temperature differences between the reacting fluids (because the experiments required to study nonisothermal dilution and the mechanisms of this process are extremely complex, and nonisothermal dilution will be addressed in another paper). Isothermal dilution includes simple dilution, dilution after short-lived water-rock interactions, and dilution after extensive water-rock interactions, where each of these subprocesses corresponds to a distinct geological process. Although this simplified model of dilution does not encompass all of the processes that occur in nature, it still covers the most important dilution pathways. Most natural dilution processes can be described by one of these subprocesses or some combination of subprocesses.

As it is possible for different types of dilution to occur during a single geological process, we designed a variety of processes to observe the precipitation that occurs in the 
presence/absence of host rocks with different diluents, dilution volumes, and reaction times. The procedures used in this experiment were as follows.

A total of $10 \mathrm{~mL}$ of mixed solution (2) was decanted into a $50 \mathrm{~mL}$ plastic bottle, and the following steps were implemented:

(1) $\mathrm{A} \mathrm{pH}$ meter was used to measure $\mathrm{pH}_{0}$, the $\mathrm{pH}$ of the solution prior to dilution. Then, 10 or $20 \mathrm{~mL}$ of pure water or $2 \mathrm{~mol} / \mathrm{L} \mathrm{NaCl}$ was used to dilute the solution

(2) $\mathrm{A} \mathrm{pH}$ meter was used to measure $\mathrm{pH}_{0}$, the $\mathrm{pH}$ of the solution prior to adding the dolomite. Next, $0.2000 \mathrm{~g}$ of 40-mesh dolomite was added to the solution, and $\mathrm{pH}_{1}$ was measured after the solution was left overnight. The solution was then diluted with 10 or $20 \mathrm{~mL}$ of pure water or $2 \mathrm{~mol} / \mathrm{L} \mathrm{NaCl}$

(3) $\mathrm{A} \mathrm{pH}$ meter was used to measure $\mathrm{pH}_{0}$, the $\mathrm{pH}$ of the solution prior to adding the dolomite. Another $0.2000 \mathrm{~g} 40$-mesh dolomite was added to the solution, and $\mathrm{pH}_{1}$ was measured after $10 \mathrm{~min}$. Another 10 or $20 \mathrm{~mL}$ of pure water or $2 \mathrm{~mol} / \mathrm{L} \mathrm{NaCl}$ was added to dilute the solution

We measured $\mathrm{pH}_{2}$ after the dilution; the solution was filtered and centrifuged, and the supernatant was sent to the ALS Laboratory Group for measurements of the $\mathrm{Pb}$ and $\mathrm{Zn}$ concentrations. Procedures (1), (2), and (3) were meant to approximate the following geological processes:

(1) The dilution of metal-carrying fluids by 1- or 2-fold their volume in atmospheric precipitation or brine while the fluids were still moving

(2) The dilution of metal-carrying fluids that entered the mineralization space and thoroughly reacted with dolomite host rocks by 1 - or 2 -fold their volume in atmospheric precipitation or brine

(3) The dilution of metal-carrying fluids that entered the mineralization space and reacted with dolomite host rocks for a brief period $(10 \mathrm{~min}$ ) by 1 - or 2 -fold their volume in atmospheric precipitation or brine

2.3. Analytical Methods. In the experiment, we used ICP-MS to measure the lead and zinc content in the blank and the supernatant, and the precipitation amount was obtained by subtracting the content of the supernatant from that of the blank.

The solutions were sent to the ALS Laboratory Group for measurements of the $\mathrm{Pb}$ and $\mathrm{Zn}$ concentrations. The $\mathrm{pH}$ measurements were performed at the Laboratory for HighTemperature and High-Pressure Hydrothermal Experiments of the Guangzhou Institute of Geochemistry, Chinese Academy of Sciences, and the electron probe microanalyzer (EPMA) measurements were carried out at the Analysis and Testing Center of the South China University of Technology.

The $\mathrm{pH}$ meter used in our experiments was a Mettler Toledo $\mathrm{pH}$ meter, and the $\mathrm{pH}$ meter was calibrated at three points every day by using freshly prepared buffer solutions (GGJ-119).

The EPMA used in these experiments was a Shimadzu EPMA-1600 (Japan), which was equipped with an EDAX Genesis energy-dispersive spectrometer (USA). The parameters of the EPMA measurements were as follows: acceleration voltage of $2.0 \mathrm{kV}$, secondary electron image resolution of $6 \mathrm{~nm}, \mathrm{X}$-ray take-off angle of $52.5^{\circ}$, and energy resolution of $120 \mathrm{eV}$.

\section{Results}

3.1. $\mathrm{pH}$ Changes. In this experiment, only a few drops of $\mathrm{HCl}$ or $\mathrm{NaOH}$ were used to adjust the $\mathrm{pH}$ of the $\mathrm{Pb} / \mathrm{Zn}$ solution, which had a volume of $20 \mathrm{~mL}$. Therefore, the dilution caused by $\mathrm{HCl}$ or $\mathrm{NaOH}$ addition was negligible, and it may be assumed that any precipitation that occurred in this experiment was purely caused by $\mathrm{pH}$ changes. The EPMA results show that precipitation can be caused by simply altering the $\mathrm{pH}$ of mixed solution (2), and the precipitates were identified as sulfides of $\mathrm{Pb}$ and $\mathrm{Zn}$ (Table 3 and Figure 2). In Table 4 and Figure 2, we can observe that the increase in the $\mathrm{pH}$ significantly promoted the precipitation of $\mathrm{Pb}$ and $\mathrm{Zn}$ sulfides. Precipitation began to occur at $\mathrm{pH}>4$, where the precipitation rates of $\mathrm{Pb}$ and $\mathrm{Zn}$ were $85 \%$ and $35 \%$, respectively, when $\mathrm{pH}>6$. At $\mathrm{pH}=7.7$, the precipitation rates of $\mathrm{Pb}$ and $\mathrm{Zn}$ were both $98 \%$. These results are consistent with the findings of Zhang et al. [31] on the mechanisms of $\mathrm{Pb}$ and $\mathrm{Zn}$ sulfide precipitation during the fluid mixing process, i.e., an increase in $\mathrm{pH}$ promotes sulfide precipitation. These experimental results also agree with the results of the CHEMXPT simulations performed by Reed [40] (Figures 3(c) and $3(\mathrm{~d}))$.

3.2. Water-Rock Reactions. The rate of $\mathrm{Pb}$ and $\mathrm{Zn}$ precipitation gradually increased with temperature. In the group without $\mathrm{NaHS}$ addition, the precipitates included $\mathrm{Pb}(\mathrm{OH})_{2}$ and $\mathrm{Zn}(\mathrm{OH})_{2}$ (Reactions (7) and (8)). In the group with NaHS addition, $\mathrm{Pb}(\mathrm{OH})_{2}$ and $\mathrm{Zn}(\mathrm{OH})_{2}$ precipitates formed as intermediaries because the solubility products of $\mathrm{PbS}$ and $\mathrm{ZnS}$ were much lower than those of $\mathrm{Pb}(\mathrm{OH})_{2}$ and $\mathrm{Zn}(\mathrm{OH})_{2}$. However, if there was a sufficient supply of sulfide, all of the precipitates were converted into sulfides (Reactions (3)-(6) or (7)-(11)). The precipitation rate of the NaHS-containing group (approximately $35 \%$ at $150^{\circ} \mathrm{C}$ ) was slightly higher than that of the group without $\mathrm{NaHS}$ at all points, whose $\mathrm{Pb}$ and $\mathrm{Zn}$ precipitation rates at $150^{\circ} \mathrm{C}$ were approximately $32 \%$ and $25 \%$, respectively (Table 5 and Figure 4 ).

As there was no visible decrease in the solution in the centrifuge tube before and after the experiment $\left(\leq 75^{\circ} \mathrm{C}\right)$, which indicates that the cover of the centrifuge tube effectively prevented the evaporation of the solution, other methods were not considered for sealing; however, this issue will need to be seriously considered in later experiments at higher temperatures.

3.3. Effects of Fluid Dilution. The results of the dilution experiment (Tables 6 and 7 and Figures 5-7) demonstrate that fluid dilution can induce $\mathrm{Pb} / \mathrm{Zn}$ sulfide precipitation. As 
TABLE 3: EPMA test results.

\begin{tabular}{|c|c|c|c|c|c|c|c|c|c|c|c|c|c|c|}
\hline \multirow{2}{*}{ Sample no. } & \multicolumn{2}{|c|}{$\mathrm{Pb}$} & \multicolumn{2}{|c|}{$\mathrm{Zn}$} & \multicolumn{2}{|c|}{ S } & \multicolumn{2}{|c|}{$\mathrm{C}$} & \multicolumn{2}{|c|}{$\mathrm{O}$} & \multicolumn{2}{|c|}{$\mathrm{Ca}$} & \multicolumn{2}{|c|}{$\mathrm{Mg}$} \\
\hline & wt. \% & At. $\%$ & wt. \% & At. $\%$ & wt. \% & At. $\%$ & wt. \% & At. $\%$ & wt. \% & At. $\%$ & wt. \% & At. $\%$ & wt. \% & At. $\%$ \\
\hline 0724-6 & 9.32 & 1.4 & 37.57 & 17.85 & 15.25 & 14.77 & 13.04 & 33.72 & 8.83 & 17.13 & 9.4 & 7.28 & 5.11 & 6.54 \\
\hline \multirow{2}{*}{ Sample no. } & \multicolumn{2}{|c|}{$\mathrm{Si}$} & \multicolumn{2}{|c|}{$\mathrm{Al}$} & \multicolumn{2}{|c|}{$\mathrm{Cl}$} & \multicolumn{2}{|c|}{ K } & \multicolumn{2}{|c|}{$\mathrm{Fe}$} & \multicolumn{2}{|c|}{$\mathrm{P}$} & \multicolumn{2}{|c|}{$\mathrm{Ti}$} \\
\hline & wt. \% & At. $\%$ & wt. \% & At. $\%$ & wt. \% & At. \% & wt. \% & At. $\%$ & wt. \% & At. $\%$ & wt. \% & At. \% & wt. \% & At. $\%$ \\
\hline $0724-6$ & - & - & - & - & 1.49 & 1.3 & - & - & - & - & - & - & - & - \\
\hline
\end{tabular}
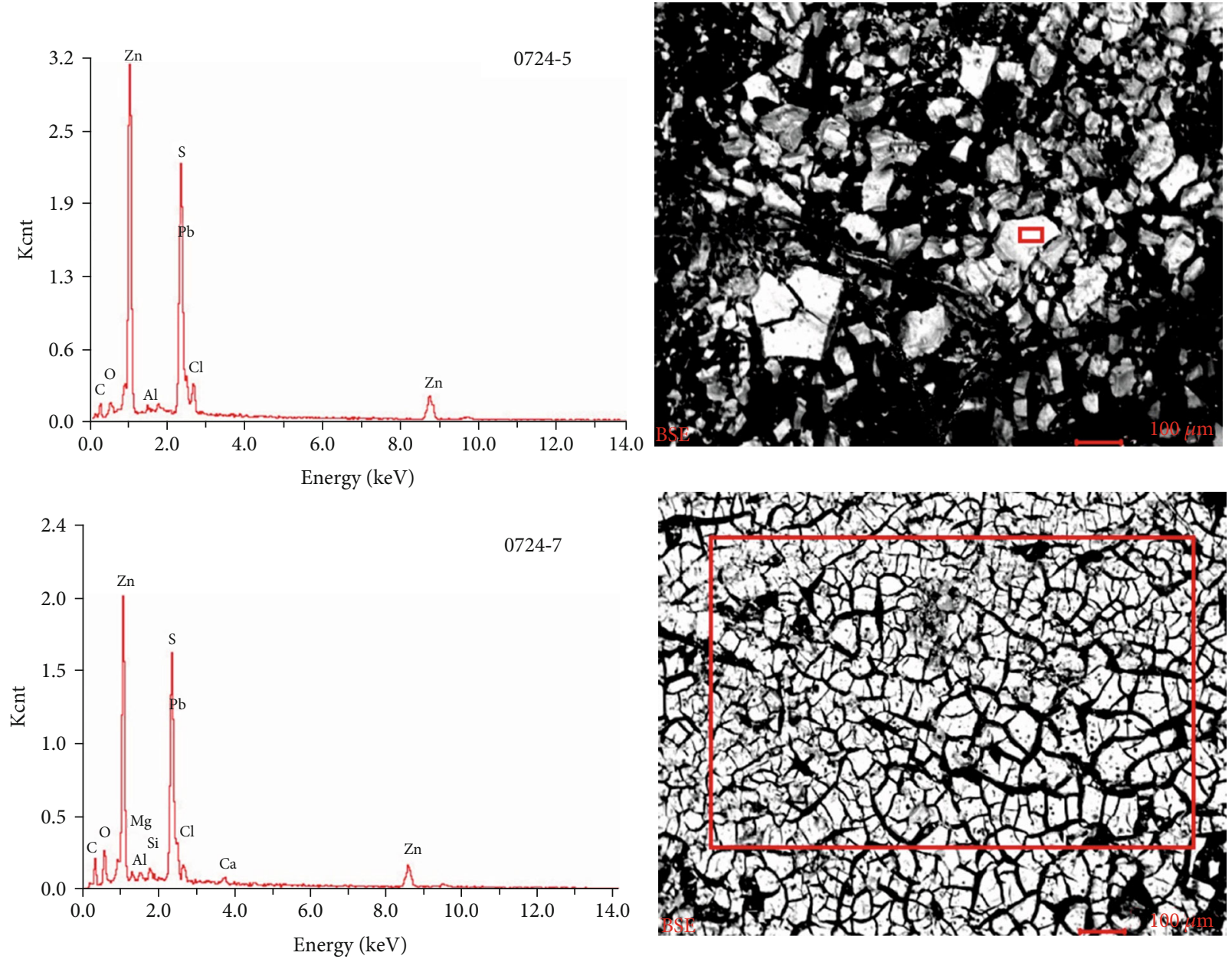

Figure 2: Electron probe patterns of 0724-5 and 0724-7.

dilution reduces the concentration of the solution, it follows from Le Chatelier's principle that $\mathrm{H}_{2} \mathrm{~S}$ will become increasingly ionized, which then increases the $\mathrm{pH}$ of the solution. This destabilizes the $\mathrm{Pb} / \mathrm{Zn}$ chloride complexes and triggers the formation of sulfide precipitates. The addition of dolomite increases the $\mathrm{pH}$ of the solution through water-rock reactions, and it was observed in XS14 and XS-15 that some precipitates were formed by the water-rock reaction itself (note: these were $\mathrm{Pb} / \mathrm{Zn}$ sulfides, not $\mathrm{Pb} / \mathrm{Zn}$ hydroxides). This occurred because the solubility product of sulfides is much smaller than that of hydroxides, such that the reaction will tend towards the formation of more stable compounds. When pure water or $\mathrm{NaCl}$ solution was added to dilute the solution, the precipitates formed by dilution supplemented the precipitates formed by water-rock reactions.

In view of the three geological processes that were meant to be simulated by this experiment, the following conclusions can be drawn:

(1) Pure dilution always results in $\mathrm{Pb} / \mathrm{Zn}$ precipitation rates of approximately 53\%-56\%, regardless of the diluent (atmospheric precipitation or brine) or volume of dilution (1- or 2 -fold the solution volume) 
TABLE 4: Effect of $\mathrm{pH}$ on mixed solution (2).

\begin{tabular}{|c|c|c|c|c|c|c|}
\hline \multirow{2}{*}{ No. } & \multirow{2}{*}{ Sample no. } & \multicolumn{2}{|c|}{$\mathrm{Pb}$} & \multicolumn{2}{|c|}{$\mathrm{Zn}$} & \multirow{2}{*}{$\mathrm{pH}$} \\
\hline & & Concentration (ppm) & Precipitation rate (\%) & Concentration (ppm) & Precipitation rate (\%) & \\
\hline 1 & $0724-0$ & 93.8 & 11.51 & 654 & 2.10 & 1 \\
\hline 2 & 0724-1 & 102.0 & 3.77 & 650 & 2.69 & 1.81 \\
\hline 3 & 0724-2 & 100.5 & 5.19 & 656 & 1.80 & 2.8 \\
\hline 4 & $0724-3$ & 101.0 & 4.72 & 657 & 1.65 & 3.99 \\
\hline 5 & $0724-4$ & 43.2 & 59.25 & 548 & 17.96 & 5.33 \\
\hline 6 & $0724-5$ & 15.9 & 85.00 & 435 & 34.88 & 6.03 \\
\hline 7 & 0724-6 & 7.2 & 93.21 & 196.5 & 70.58 & 6.81 \\
\hline 8 & $0724-7$ & 1.4 & 98.68 & 12.1 & 98.19 & 7.73 \\
\hline 9 & $0724-8$ & 0.8 & 99.25 & 4.4 & 99.34 & 8.98 \\
\hline 10 & $0724-9$ & 1.7 & 98.40 & 5.8 & 99.13 & 10 \\
\hline 11 & 0724-10 (control) & 106.0 & - & 668 & - & 1.81 \\
\hline
\end{tabular}

(2) In case the metal-carrying fluid enters the mineralization space and only interacts briefly with the dolomite, dilution with an equal volume of pure water or $\mathrm{NaCl}$ brine yields the same result as in (1). However, dilution with twice the solution volume causes the effects of water-rock reactions and dilution to stack with each other, which increases the precipitation rate to approximately $70 \%$

(3) If the metal-carrying fluid is allowed to react extensively with the dolomite host rock after entering the mineralization space, dilution with an equal volume of pure water or $\mathrm{NaCl}$ brine increases the precipitation rate of $\mathrm{Pb}$ to $\sim 70 \%$. However, the $\mathrm{Zn}$ precipitation rate is still the same as that in (1). Dilution with twice the solution volume causes the effects of dilution and water-rock reactions to combine, thus increasing the $\mathrm{Pb}$ and $\mathrm{Zn}$ precipitation rate to approximately 80 and $70 \%$, respectively

In summary, simple dilution does induce precipitation to a certain extent. However, dilution induces precipitation much more effectively after the metal-carrying fluid has reacted extensively with its host rocks in the mineralization space. As the diluent and metal-carrying fluid are unlikely to simultaneously reach the mineralization space, this scenario is a more realistic representation of actual geological processes.

\section{Discussion}

4.1. Sulfide Precipitation and Changes in the Fluid $p H$. As $\mathrm{NaHS}$ is a strong base and weak acid [41, 42], its weak acid anions are easily hydrolyzed in aqueous solutions [41, 42] (see Reaction (1)) to form a weakly alkaline solution, as follows:

$$
\mathrm{HS}^{-}+\mathrm{H}_{2} \mathrm{O} \rightleftharpoons \mathrm{H}_{2} \mathrm{~S}(\mathrm{aq})+\mathrm{OH}^{-} .
$$

Additionally, the weak acid anions can dissociate to form a weakly acidic solution, as follows:

$$
\mathrm{HS}^{-} \rightleftharpoons \mathrm{S}^{2-}+\mathrm{H}^{+}
$$

Reaction (1) occurs under acidic conditions, whereas basic conditions are conducive for Reaction (2) [41, 42]. As the $\mathrm{pH}$ of mixed solution (2) was less than 4, Reaction (1) was the main reaction that controlled the ratio of $\mathrm{H}_{2} \mathrm{~S}$ to $\mathrm{HS}^{-}$. During the experiment, the dropwise addition of $\mathrm{HCl}$ reduced the $\mathrm{pH}$ of the solution, thus causing the sulfides and $\mathrm{Pb} / \mathrm{Zn}$ to exist as $\mathrm{H}_{2} \mathrm{~S}$ and stable chloride complexes, respectively, in the solution. Dropwise $\mathrm{NaOH}$ addition increased the $\mathrm{pH}$, which then caused the sulfides to exist as $\mathrm{H}_{2} \mathrm{~S}, \mathrm{HS}^{-}$, and $\mathrm{S}^{2-}$ in $\mathrm{pH}$-dependent ratios [31]. The $\mathrm{Pb} / \mathrm{Zn}$ chloride complexes gradually became less stable as the solution developed a basic environment, which induced $\mathrm{Pb}$ and $\mathrm{Zn}$ to bind with sulfides, as shown in the reactions below (this occurred until all of the $\mathrm{Pb}$ and $\mathrm{Zn}$ precipitated from the solution):

$$
\begin{aligned}
\mathrm{Na}_{2} \mathrm{MeCl}_{n^{4-n}} & =\mathrm{Me}^{2+}+2 \mathrm{Cl}^{-}+2 \mathrm{NaCl} \quad(n=1,2,3,4), \\
\mathrm{Me}^{2+}+\mathrm{H}_{2} \mathrm{~S} & \rightarrow \mathrm{MeS} \downarrow+2 \mathrm{H}^{+}, \\
\mathrm{Me}^{2+}+\mathrm{HS}^{-} & \rightarrow \mathrm{MeS} \downarrow+\mathrm{H}^{+}, \\
\mathrm{Me}^{2+}+\mathrm{S}^{2-} & \rightarrow \mathrm{MeS} \downarrow
\end{aligned}
$$

In the water-rock interaction experiment, both experimental groups exhibited precipitation due to $\mathrm{pH}$ increases that were in turn induced by water-rock reactions. In the $\mathrm{NaHS}$-containing group, the $\mathrm{Pb} / \mathrm{Zn}$ chloride complexes were destabilized by the increase in $\mathrm{pH}$, which led to the formation of sulfide precipitates. In the group without $\mathrm{NaHS}$ addition, the increase in $\mathrm{pH}$ induced $\mathrm{Pb} / \mathrm{Zn}$ hydrolysis, which led to the formation of hydroxide precipitates. The reaction by 

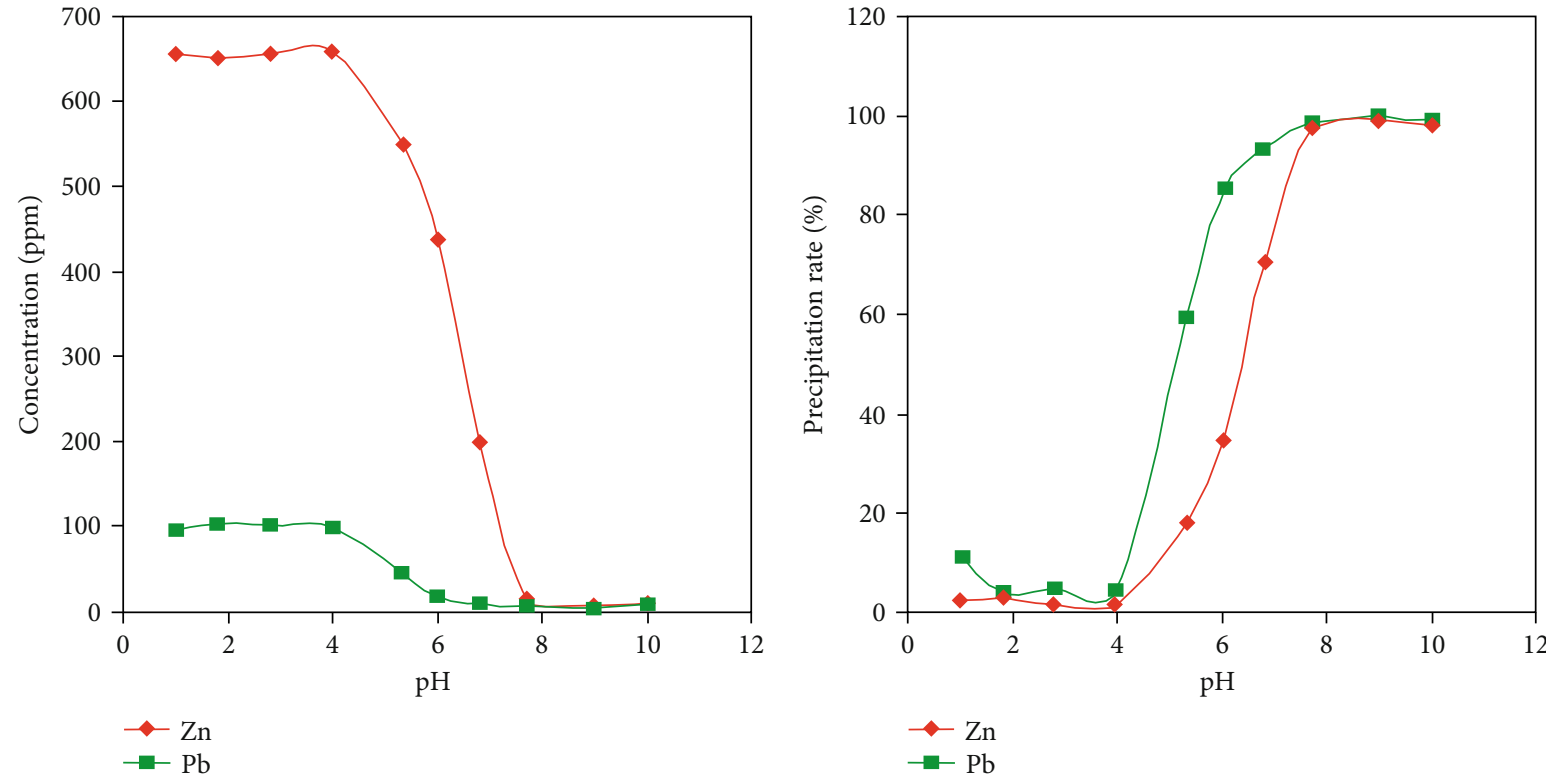

(a)

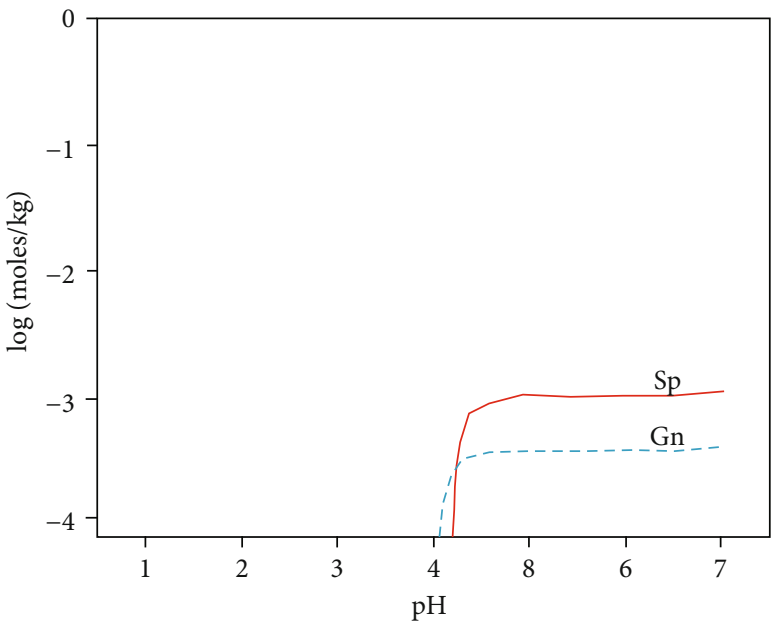

(c)

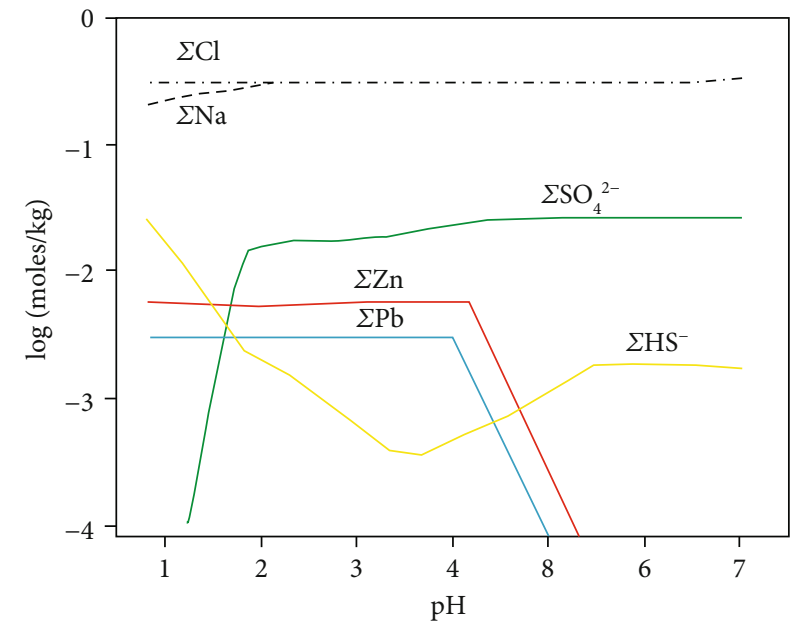

(d)

Figure 3: Effects of $\mathrm{pH}$ changes on $\mathrm{Pb}-\mathrm{Zn}$ precipitation (c and d according to Reed [40]). (a, b) Effects of pH changes on $\mathrm{Pb}$ and $\mathrm{Zn}$ precipitation when the acidity of mixed solution (2) was adjusted. (a) Concentration vs. pH. (b) Precipitation rate vs. pH. (c, d) Computational simulations of the effects of $\mathrm{pH}$ changes, where $\mathrm{NaOH}$ was added to an acidic fluid $(1 \mathrm{~mol} \mathrm{NaCl}$, initially) with aqueous $\mathrm{Pb}$ and $\mathrm{Zn}$ to increase its $\mathrm{pH}$ from 0.8 to 7 at $T=200^{\circ} \mathrm{C}$. (c) Minerals. (d) Total concentrations of the aqueous components.

which $\mathrm{pH}$ changes induced hydroxide formation (as an intermediary for sulfide formation) is as follows:

$$
\mathrm{Me}^{2+}+2 \mathrm{H}_{2} \mathrm{O} \leftrightarrow \mathrm{Me}(\mathrm{OH})_{2}+2 \mathrm{H}^{+}
$$

The hydroxides then undergo a dehydration reaction to form oxides:

$$
\mathrm{Me}(\mathrm{OH})_{2} \rightarrow \mathrm{MeO} \downarrow+\mathrm{H}_{2} \mathrm{O} .
$$

$\mathrm{The} \mathrm{Pb} / \mathrm{Zn}$ hydroxides and oxides in the fluids or on the surface of carbonate rocks are easily converted into sulfides, as shown in the following equations [43]:

$$
\begin{aligned}
\mathrm{Me}(\mathrm{OH})_{2}+\mathrm{H}_{2} \mathrm{~S}(\mathrm{aq}) & \rightarrow \mathrm{MeS} \downarrow+2 \mathrm{H}_{2} \mathrm{O} \\
\mathrm{MeO}(\mathrm{s})+\mathrm{H}_{2} \mathrm{~S}(\mathrm{aq}) & \rightarrow \mathrm{MeS} \downarrow+\mathrm{H}_{2} \mathrm{O} .
\end{aligned}
$$

Alternatively,

$$
\begin{gathered}
\mathrm{Me}(\mathrm{OH})_{2}+\mathrm{HS}^{-} \rightarrow \mathrm{MeS} \downarrow+2 \mathrm{H}_{2} \mathrm{O}+\mathrm{OH}^{-}, \\
\mathrm{MeO}(\mathrm{s})+\mathrm{HS}^{-} \rightarrow \mathrm{MeS} \downarrow+\mathrm{OH}^{-} .
\end{gathered}
$$

$\mathrm{Pb}$ and $\mathrm{Zn}$ are much more likely to undergo hydrolysis at high temperatures and pressures, but the tendency of $\mathrm{Pb}$ and $\mathrm{Zn}$ hydroxides to redissolve into the solution makes it difficult to measure their hydrolysis constants. Although the sample did undergo partial redissolution at 
TABLE 5: Test results of the water-rock interaction experiment.

\begin{tabular}{|c|c|c|c|c|c|c|c|c|c|}
\hline $\begin{array}{l}\text { Sample } \\
\text { no. }\end{array}$ & $\begin{array}{l}\text { Test value } \\
\text { rate (ppm) }\end{array}$ & $\begin{array}{c}\mathrm{Pb} \\
\text { Precipitation } \\
(\mathrm{ppm})\end{array}$ & $\begin{array}{l}\text { Precipitation } \\
\text { rate }(\%)\end{array}$ & $\begin{array}{c}\text { Test value } \\
(\mathrm{ppm})\end{array}$ & $\begin{array}{c}\mathrm{Zn} \\
\text { Precipitation } \\
(\mathrm{ppm})\end{array}$ & $\begin{array}{l}\text { Precipitation } \\
\text { rate }(\%)\end{array}$ & $\begin{array}{l}\text { Dolomite } \\
\text { mass (g) }\end{array}$ & $\begin{array}{l}\text { Solution } \\
\text { type }\end{array}$ & Temperature \\
\hline Sb-16 & 77.2 & 32.3 & 29.5 & 623 & 95 & 13.2 & 0.5037 & (2) & \multirow{2}{*}{$25^{\circ} \mathrm{C}$} \\
\hline Sb-17 & 87.4 & 22.1 & 20.2 & 594 & 81 & 12.0 & 0.5023 & (1) & \\
\hline Sb-18 & 75.3 & 34.2 & 31.2 & 567 & 151 & 21.0 & 0.5036 & (2) & \multirow{2}{*}{$50^{\circ} \mathrm{C}$} \\
\hline Sb-19 & 79.1 & 30.4 & 27.8 & 532 & 143 & 21.2 & 0.5033 & (1) & \\
\hline Sb-20 & 74.9 & 34.6 & 31.6 & 547 & 171 & 23.8 & 0.5024 & (2) & \multirow{2}{*}{$75^{\circ} \mathrm{C}$} \\
\hline $\mathrm{Sb}-21$ & 75.5 & 34.0 & 31.1 & 523 & 152 & 22.5 & 0.5047 & (1) & \\
\hline $\mathrm{Sb}-22$ & 72.4 & 37.1 & 33.9 & 538 & 180 & 25.1 & 0.5015 & (2) & \multirow{2}{*}{$100^{\circ} \mathrm{C}$} \\
\hline $\mathrm{Sb}-23$ & 74.4 & 35.1 & 32.1 & 518 & 157 & 23.3 & 0.5033 & (1) & \\
\hline $\mathrm{Sb}-24$ & 70.9 & 38.6 & 35.3 & 547 & 171 & 33.7 & 0.5047 & (2) & \multirow{2}{*}{$150^{\circ} \mathrm{C}$} \\
\hline $\mathrm{Sb}-25$ & 73.8 & 35.7 & 32.6 & 507 & 168 & 24.9 & 0.5058 & (1) & \\
\hline 0720-1 & 109.5 & - & - & 675 & - & - & - & - & \multirow{2}{*}{ Blank } \\
\hline XS-13 & 109.5 & - & - & 718 & - & - & - & - & \\
\hline
\end{tabular}

Note: $0720-1$ is blank for mixed solution (1) and XS-13 is blank for mixed liquid (2).
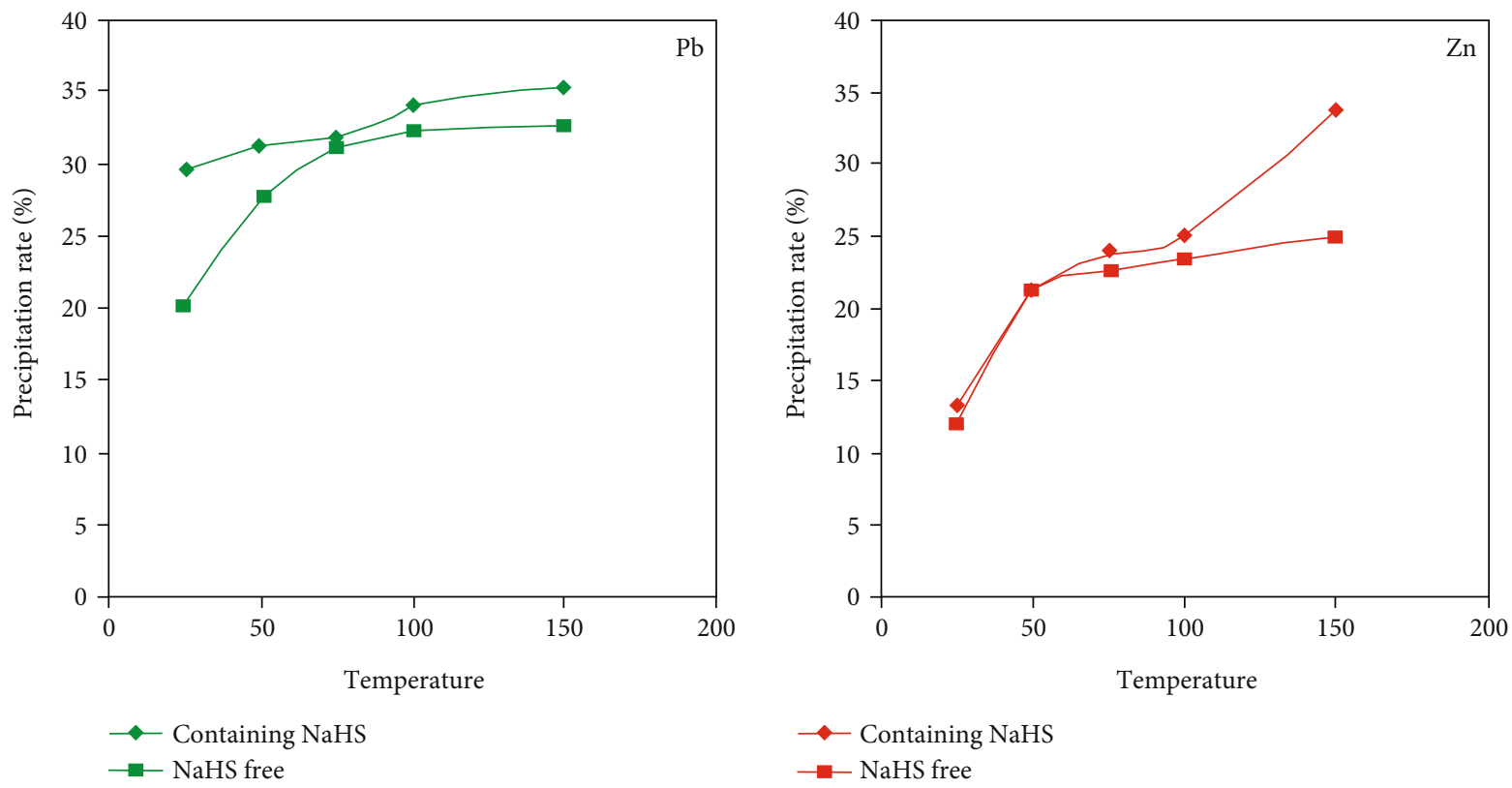

FIgURE 4: Temperature-precipitation rate diagram for the water-rock interactions.

each temperature during the aforementioned experiment during the water-rock reactions, our observations indicate that $\mathrm{Pb} / \mathrm{Zn}$ hydrolysis becomes more acute with increasing temperatures.

Dilution essentially changes the $\mathrm{pH}$ of the solution to a $\mathrm{pH}$ range that is more amenable for the precipitation of $\mathrm{Pb} / \mathrm{Zn}$ sulfides. In summary, changes in the $\mathrm{pH}$ of the metal-carrying fluid were found to be the primary cause of sulfide precipitation in all of the experiments that were performed in this study. This includes the $\mathrm{pH}$ change experiments, as well as the water-rock interaction and dilution experiments that superficially appeared to be independent of $\mathrm{pH}$.
4.2. Differences between the Sulfide Precipitation Mechanisms of MVT and HZT Deposits. The present data show that the $\mathrm{pH}$ values of basin brines for a typical MVT deposit range between 5 and 6 [44]. At these $\mathrm{pH}$ values, the chloride complexes of $\mathrm{Pb}$ and $\mathrm{Zn}$ are likely to be insoluble [33, 44-50], where some of the $\mathrm{Pb}$ and $\mathrm{Zn}$ will precipitate as $\mathrm{Pb}(\mathrm{OH})_{2}$ and $\mathrm{Zn}(\mathrm{OH})_{2}$ [32]. Therefore, it is impossible for the basin brines of the MVT deposits to carry high concentrations of mineralizing metals. When fluids carrying metal chloride complexes enter a mineralizing space, water-rock interactions occur owing to the presence of carbonate strata. This depletes the $\mathrm{H}^{+}$of the fluid and increases its $\mathrm{pH}$, thus rendering it a neutral or weakly basic solution [51]. If the fluid 


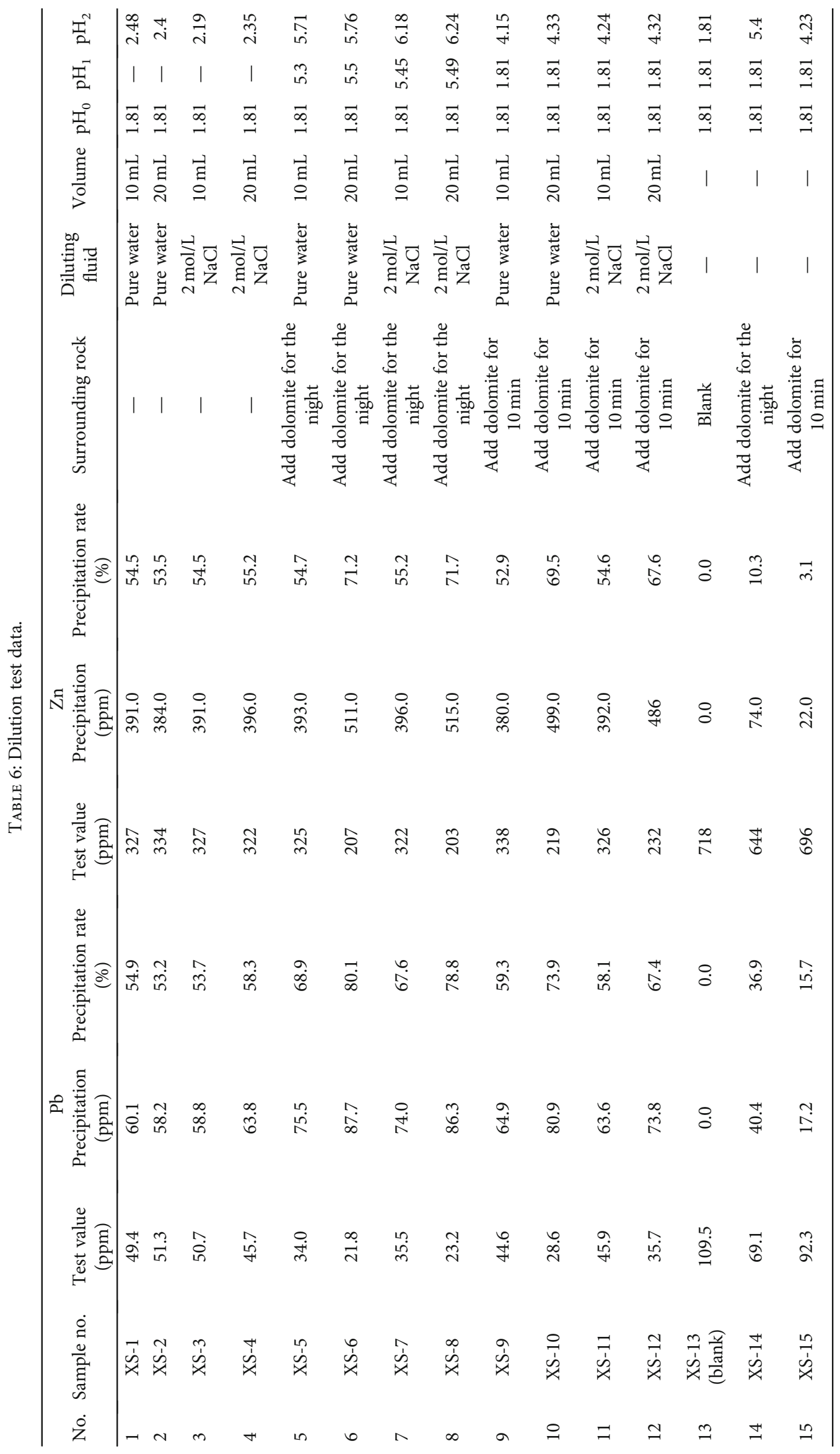


TABLE 7: EPMA test results.

\begin{tabular}{|c|c|c|c|c|c|c|c|c|c|c|c|c|c|c|}
\hline \multirow{2}{*}{ Sample no. } & \multicolumn{2}{|c|}{$\mathrm{Pb}$} & \multicolumn{2}{|c|}{$\mathrm{Zn}$} & \multicolumn{2}{|c|}{$S$} & \multicolumn{2}{|c|}{$\mathrm{C}$} & \multicolumn{2}{|c|}{$\mathrm{O}$} & \multicolumn{2}{|c|}{$\mathrm{Ca}$} & \multicolumn{2}{|c|}{$\mathrm{Mg}$} \\
\hline & wt. \% & At. $\%$ & wt. \% & At. $\%$ & wt. \% & At. $\%$ & wt. \% & At. $\%$ & wt. \% & At. $\%$ & wt. \% & At. \% & wt. $\%$ & At. $\%$ \\
\hline XS-4 & 18.75 & 3.04 & 33.57 & 17.28 & 15.15 & 15.89 & 12.2 & 34.18 & 8.04 & 16.9 & 6.66 & 5.59 & 4.07 & 5.63 \\
\hline XS-6 & 5.66 & 0.61 & 11.93 & 4.06 & 4.15 & 2.88 & 17.26 & 31.97 & 26.8 & 37.26 & 22.34 & 12.4 & 11.61 & 10.62 \\
\hline XS-8 & - & - & - & - & - & - & 16.61 & 27.11 & 36.62 & 44.88 & 27.61 & 13.5 & 12.62 & 10.18 \\
\hline XS-10 & 2.49 & 0.32 & 33.38 & 13.79 & 10.5 & 8.84 & 13.96 & 31.4 & 14.93 & 25.21 & 10.15 & 6.84 & 5.28 & 5.86 \\
\hline XS-12 & 1.01 & 0.12 & 24 & 9.14 & 6.59 & 5.12 & 11.79 & 24.43 & 21.4 & 33.31 & 12.82 & 7.96 & 6.89 & 7.05 \\
\hline \multirow{2}{*}{ Sample no. } & \multicolumn{2}{|c|}{$\mathrm{Si}$} & \multicolumn{2}{|c|}{$\mathrm{Al}$} & \multicolumn{2}{|c|}{$\mathrm{Cl}$} & \multicolumn{2}{|c|}{ K } & \multicolumn{2}{|c|}{$\mathrm{Fe}$} & \multicolumn{2}{|c|}{$\mathrm{P}$} & \multicolumn{2}{|c|}{$\mathrm{Ti}$} \\
\hline & wt. \% & At. $\%$ & wt. \% & At. $\%$ & wt. \% & At. $\%$ & wt. \% & At. $\%$ & wt. \% & At. $\%$ & wt. \% & At. \% & wt. $\%$ & At. $\%$ \\
\hline XS-4 & - & - & - & - & 1.57 & 1.49 & - & - & - & - & - & - & - & - \\
\hline XS-6 & 0.26 & 0.2 & - & - & - & - & - & - & - & - & - & - & - & - \\
\hline XS-8 & 3.05 & 2.13 & 2.03 & 1.47 & - & - & 1.47 & 0.73 & - & - & - & - & - & - \\
\hline XS-10 & 3.72 & 3.14 & 2.47 & 2.17 & 0.8 & 0.54 & 1.13 & 0.69 & - & - & - & - & - & - \\
\hline XS-12 & 6.79 & 6.02 & 4.76 & 4.39 & 1.02 & 0.71 & 2.27 & 1.44 & 0.67 & 0.3 & - & - & - & - \\
\hline
\end{tabular}

XS-13 is a control solution with no additions or alterations, and XS-14 is a control solution that was filtered, but not diluted after dolomite was added and left overnight in the solution. XS-15 is a control, where the solution was filtered, but not diluted after dolomite was added and left for $10 \mathrm{~min}$ in the solution.
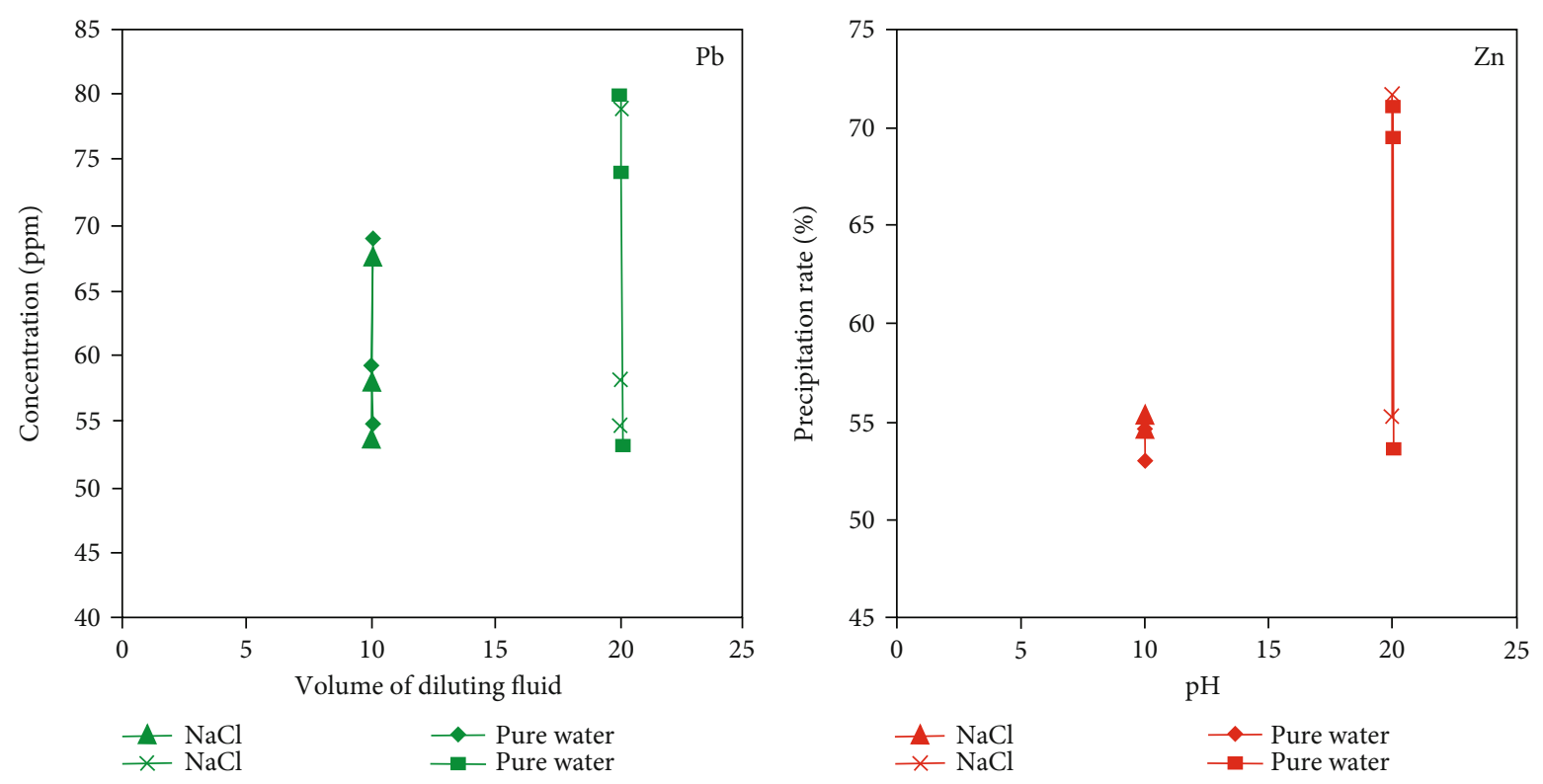

Figure 5: Precipitation rates for the dilution experiment.

contains small amounts of sulfide (i.e., the scenario that was simulated in this study) or mixes with another sulfidecontaining fluid [31], $\mathrm{H}_{2} \mathrm{~S}$ and $\mathrm{HS}^{-}$species will be present in the fluid [31]. As mentioned previously, the fluid will simultaneously undergo $\mathrm{pH}$ changes, water-rock interactions, dilution, and mixing; notably, the sulfide complexes of $\mathrm{Pb}$ and $\mathrm{Zn}$ are more stable at low temperatures, neutralto-basic $\mathrm{pH}$ levels, and low salinity levels [52-56]:

$$
\mathrm{Me}^{2+}+n \mathrm{HS}^{-} \rightleftarrows \mathrm{Me}(\mathrm{HS})_{n}^{2-n} \quad(n=2,3,4) .
$$

At this point, the metal precipitation reaction (Reaction (6)) cannot occur, and the chloride complexes of $\mathrm{Pb}$ and $\mathrm{Zn}$ in the fluid become unstable. Some of these complexes turn into sulfur-hydrogen complexes (Reaction (12)) while the other portion reacts directly with the $\mathrm{H}_{2} \mathrm{~S}$ and $\mathrm{HS}^{-}$in the fluid to form sulfide precipitates (Reactions (4) and (5)). This process gradually depletes the $\mathrm{H}_{2} \mathrm{~S}$ species in the fluid, which destabilizes the $\mathrm{Pb} / \mathrm{Zn}$ sulfur-hydrogen complexes. These complexes then release some of their $\mathrm{HS}^{-}$to form $\mathrm{H}_{2} \mathrm{~S}$, which continues until an equilibrium is reached among the $S$ species, metal ions, and sulfur-hydrogen complexes.

As MVT basin brines do not contain high metal concentrations and have high initial $\mathrm{pH}$ levels, a small change in their physical and chemical conditions is sufficient to bring their $\mathrm{pH}$ levels to a range that is amenable for $\mathrm{Pb} / \mathrm{Zn}$ sulfide precipitation. This explains why low-grade disseminated ores 

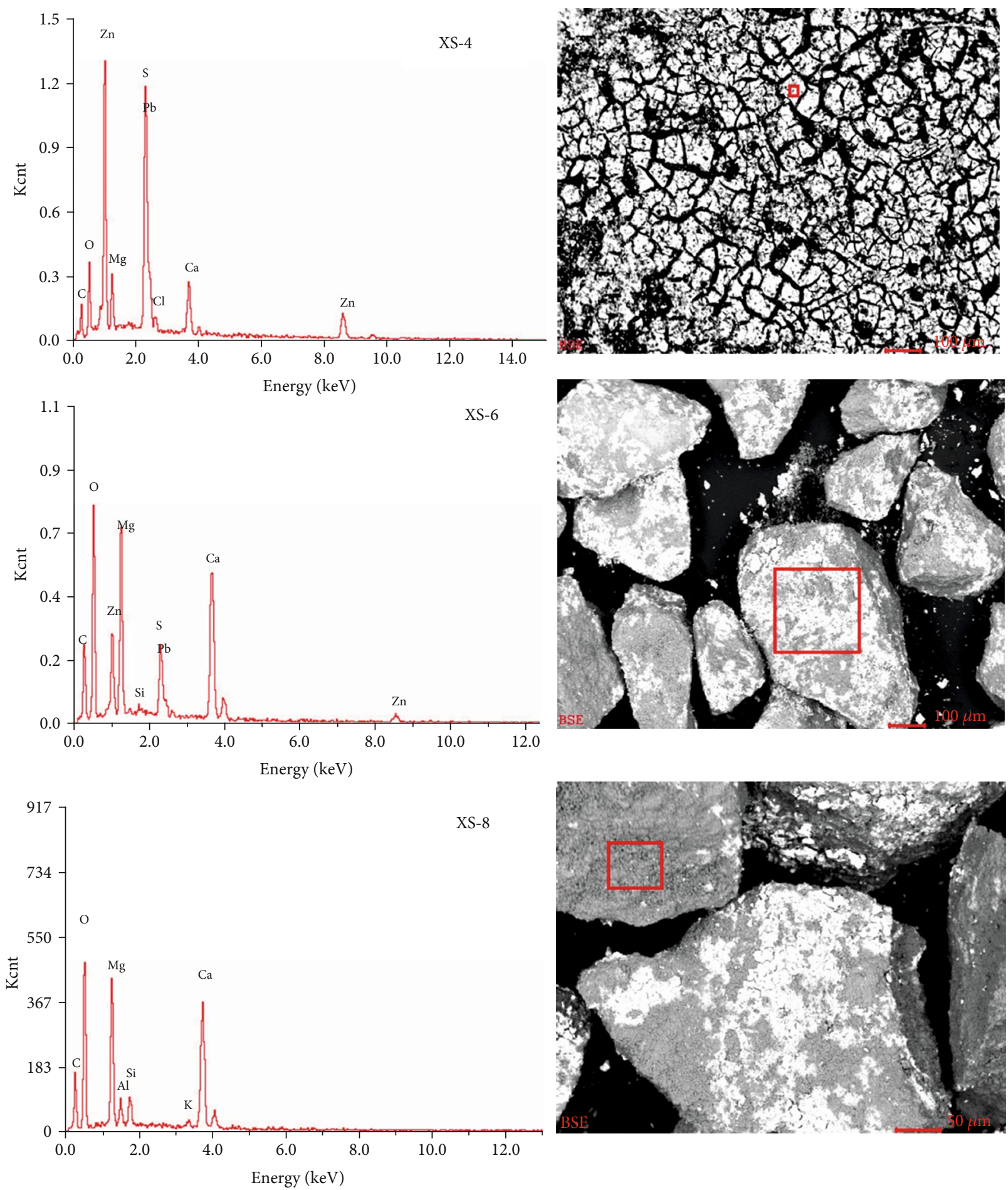

FIGURE 6: Electron probe patterns for XS-4, XS-6, and XS-8.

are easily formed by the MVT basin brines. Furthermore, as these fluids are present in enormous quantities, they will naturally form large deposits and mineral districts.

In contrast, the ore-forming fluids of the HZT deposits are usually quite acidic $(\mathrm{pH}<3.6)[15,25,57]$. This minimizes $\mathrm{Pb} / \mathrm{Zn}$ hydrolysis and enhances $\mathrm{Pb} / \mathrm{Zn}$ solubility (each unit decrease in $\mathrm{pH}$ is known to cause a geometric increase in the metal concentration [33]). Therefore, a fluid of this type can carry enormous amounts of metal over long distances, during which the metals may coexist in an aqueous state with some amount of $\mathrm{H}_{2} \mathrm{~S}$ (such as in mixed solution (2)). As these fluids have a low initial $\mathrm{pH}$, a large change in their physical and chemical conditions (especially $\mathrm{pH}$ ) is necessary to trigger precipitation. Therefore, these fluids will be able to extract mineral-forming substances as they migrate through the earth, which will ultimately become highly concentrated, 

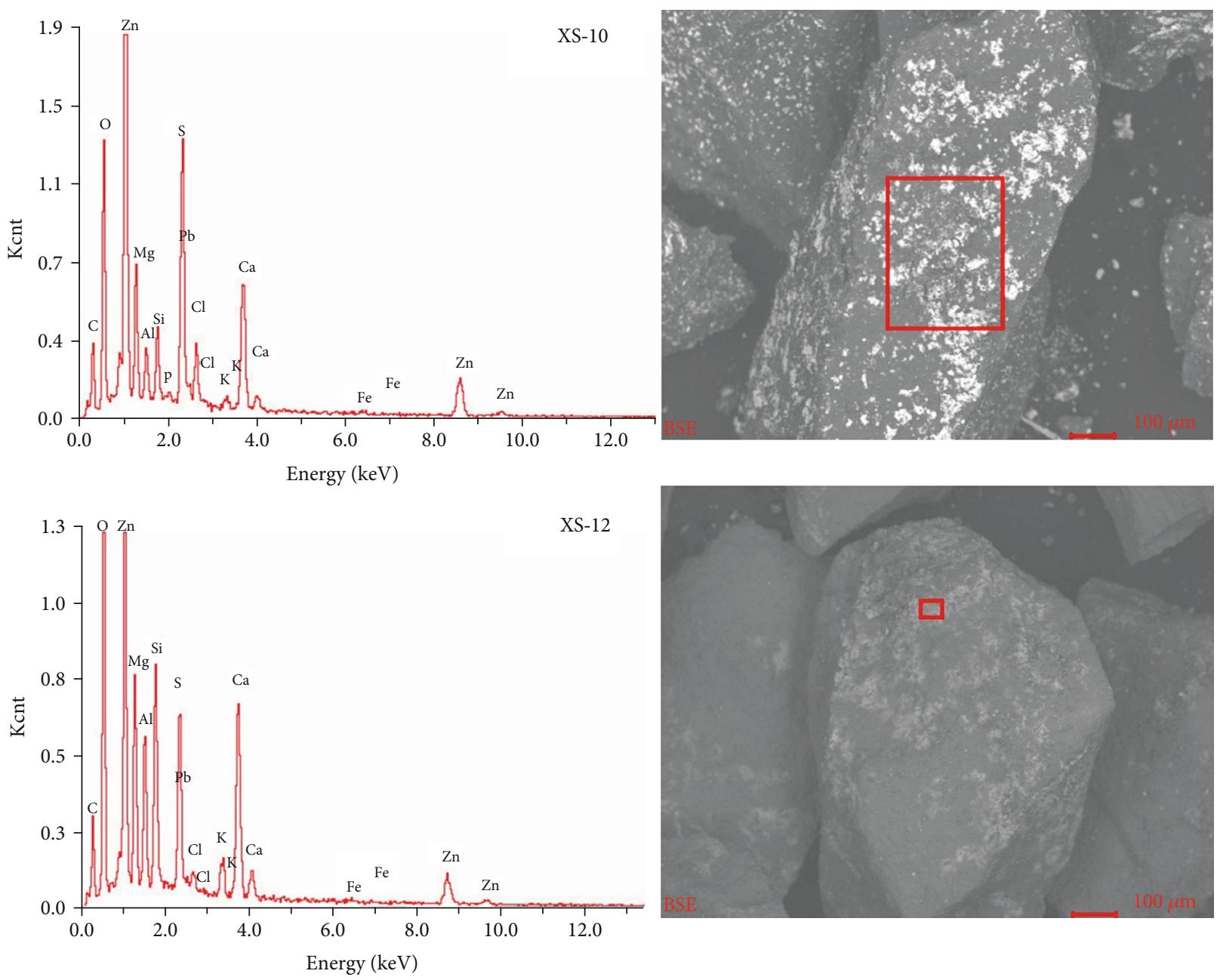

FIGURE 7: Electron probe patterns for XS-10 and XS-12.

slurry-like ore-forming fluids that precipitate dense, blocklike $\mathrm{Pb} / \mathrm{Zn}$ ores. This is generally beneficial for the formation of high-grade ores and orebodies. The strong dilation of the fluid is also conducive to the formation of highly enriched and thick orebodies.

\section{Conclusions}

The results of this study indicate that, within a fluid whose $\mathrm{Pb} / \mathrm{Zn}$ and sulfide contents exist as chloride complexes and $\mathrm{H}_{2} \mathrm{~S}$, respectively, sulfide precipitation can be induced by subjecting this fluid to $\mathrm{pH}$ changes, water-rock reactions, or isothermal dilution. The most effective method for triggering the precipitation of sulfides from such a fluid is a change in $\mathrm{pH}$, followed by dilution and then water-rock interactions. Water-rock interactions and dilution both induce precipitation by shifting the $\mathrm{pH}$ of the fluid into a range that is amenable for $\mathrm{Pb} / \mathrm{Zn}$ sulfide precipitation.

Although the aforementioned insights were obtained from experiments performed at low temperatures and pressures, these conditions partially resemble the mineralization temperatures and pressures of nonmagmatic, carbonatehosted epigenetic $\mathrm{Pb} / \mathrm{Zn}$ deposits. Nonetheless, a change in the pressure and temperature will alter the threshold for large-scale $\mathrm{Pb} / \mathrm{Zn}$ hydrolysis reactions and the dynamics of water-rock interactions. In our next study, we will perform systematic experiments to study the effects of mineralization temperatures and pressures using a high-temperature/highpressure experimental apparatus to obtain more realistic experimental data on the mechanisms of metal sulfide precipitation.

\section{Data Availability}

The data used to support the findings of this study are included within the article.

\section{Conflicts of Interest}

The authors declare that there are no conflicts.

\section{Acknowledgments}

This study was supported jointly by the National Natural Science Foundation of China (grant numbers 41802089, 41572060, and U1133602), the Ten Thousand Talent 
Program of Yunnan Province (grant number YNWR-QNBJ2019-157), the Projects for Yunnan Engineering Laboratory of Mineral Resources Prediction and Evaluation (2012), and the Yunnan and Kunming University of Science and Technology Postdoctoral Sustentation Fund.

\section{References}

[1] J. R. Xie, A Discussion on the Deposits Classify, Science Press, 1964.

[2] G. C. Tu, Geochemistry of Strata-Bound Ore Deposits in China, Science Press, 1984.

[3] C. Q. Zhang, S. P. Wu, H. M. Li, F. Liu, B. J. Guo, and D. R. Gao, "Distribution, characteristics and genesis of Mississippi Valley-type lead-zinc deposits in Sichuan-Yunnan-Guizhou area," Mineral Deposits, vol. 24, no. 3, pp. 336-348, 2005.

[4] R. S. Han, J. Chen, Z. L. Huang et al., Dynamics of Tectonic Ore-Forming Process and Localization-Prognosis of Concealed Orebodies: As Exemplified by the Huize Surper-Large $\mathrm{Zn-Pb}$ (Ag-Ge) District, Yunna, Science Press, 2006.

[5] R. S. Han, Y. Z. Hu, X. K. Wang et al., "Mineralization model of rich Ge-Ag-bearing $\mathrm{Zn}-\mathrm{Pb}$ polymetallic deposit concentrated district in Northeastern Yunnan, China," Acta Geologica Sinica, vol. 86, no. 2, pp. 280-293, 2012.

[6] C. Q. Zhang, Z. Y. Rui, Y. C. Cheng, D. H. Wang, Z. H. Chen, and D. B. Lou, "The main successive strategic bases of resources for $\mathrm{Pb}-\mathrm{Zn}$ deposits in China," Geology in China, vol. 40, no. 1, pp. 248-272, 2013.

[7] R. S. Han, F. Wang, Y. Z. Hu et al., "Metallogenic tectonic dynamics and chronology constrains on the Huize-typ (HZT) germanium-rich silver-zinc-lead deposits," Geotectonica et Metallogenia, vol. 38, no. 4, pp. 758-771, 2014.

[8] H. C. Liu and W. D. Lin, Metallogenic Rules of $\mathrm{Zn}-\mathrm{Pb}-(\mathrm{Ag})$ Deposits in Northeastern Yunnan, Yunnan University Publishing House, 1999.

[9] J. Z. Wang, C. Y. Li, Z. Q. Li, and J. J. Liu, "The geological setting, characters and origin of Mississippi Valley-type $\mathrm{Pb}-\mathrm{Zn}$ deposits in Sichuan and Yunnan Provinces," Geology-Geochemistry, vol. 29, no. 2, pp. 41-45, 2001.

[10] G. C. Tu, "Two unique mineralization areas in southwest China," Bulletin of Mineralogy, Petrology and Geochemistry, vol. 22, pp. 1-2, 2002.

[11] Z. L. Huang, J. Chen, and R. S. Han, Geochemistry and Ore Gen-esis of Huize Super-Large Lead-Zinc Deposit, Yunnan Province, Concurrently Discuss the Relationship Between Emeishan Basalt and Lead-Zinc Deposits, Geological Publishing House, 2004.

[12] W. B. Li, Z. L. Huang, J. Chen, C. Xu, T. Guan, and M. D. Yin, "Sulfur isotopes and rare-earth elements geochemistry of the giant Huize $\mathrm{Zn}-\mathrm{Pb}$ deposit in Yunnan Province," Acta Geologica Sinica, vol. 78, no. 4, pp. 507-518, 2004.

[13] R. S. Han, C. Q. Liu, Z. L. Huang et al., "Geological features and origin of the Huize carbonate-hosted $\mathrm{Zn}-\mathrm{Pb}-(\mathrm{Ag})$ district, Yunnan," Ore Geology Reviews, vol. 31, pp. 360-383, 2007.

[14] R. S. Han, C. Q. Liu, J. M. Carranza et al., "REE geochemistry of altered fault tectonites of Huize-type $\mathrm{Zn}-\mathrm{Pb}-(\mathrm{Ge}-\mathrm{Ag})$ deposit, Yunnan Province, China," Geochemistry: Exploration, Environment, Analysis, vol. 12, pp. 127-146, 2012.

[15] Y. Zhang, R. Han, P. Wei, and W. Qiu, "Fluid inclusion features and physicochemical conditions of the Kuangshanchang
$\mathrm{Pb}-\mathrm{Zn}$ deposit, Huize, Yunnan Province," Journal of Jilin University, vol. 47, no. 3, pp. 719-733, 2017.

[16] Y. Zhang, R. Han, P. Wei, and L. Wang, "Identification of two types of metallogenic fluids in the ultra-large Huize $\mathrm{Pb}-\mathrm{Zn}$ deposit, SW China," Geofluids, vol. 2017, Article ID 6345810, 22 pages, 2017.

[17] C. Q. Zhang, The Genetie Model of Mississippi Valley Type Deposit in the Boundary Area of Sichuan, Yunnnan and Guizhou Province, China, Chinese Aeademy of Geologieal Sciences, Beijing, China, 2008.

[18] R. S. Han, Y. Zhang, F. Wang, P. Wu, W. L. Qiu, and W. Y. Li, The Metallogenic Mechanism and Localization-Prognosis of Concealed Orebodies in Rich $\mathrm{Zn}-\mathrm{Pb}$-(Ge) Deposits at Northeastern Yunnan Deposit Concentration District, SW China, Science Press, 2019.

[19] Z. L. Huang, W. B. Li, J. Chen et al., "Carbon and oxygen isotope constraints on mantle fluidinvolvement in the mineralization of the Huize super-large $\mathrm{Pb}-\mathrm{Zn}$ deposits, Yunnan Province, China," Journal of Geochemical Exploration, vol. 78-79, no. 3, pp. 637-642, 2003.

[20] Z. L. Huang, X. B. Li, M. F. Zhou, W. B. Li, and Z. G. Jin, "REE and C-O isotopic geochemistry of calcites from the world-class Huize $\mathrm{Pb}-\mathrm{Zn}$ deposits, Yunnan, China: implications for the ore genesis," Acta Geologica Sinica - English Edition, vol. 84, no. 3, pp. 597-613, 2010.

[21] Z. L. Huang, J. Chen, R. S. Han et al., "REE geochemistry of calcite-a gangue mineral in the Huize ore deposit, Yunnan," Acta Mieralogica Sinica, vol. 21, no. 4, pp. 659-666, 2001.

[22] D. F. Luo, Z. L. Huang, F. Wang, J. X. Zhou, and X. B. Li, "Mechanism of transportation and precipitation of mineralization elements in the Huize super-large $\mathrm{Pb}-\mathrm{Zn}$ deposit, Yunnan Province, China," Acta Mieralogica Sinica, vol. 32, no. 2, pp. 288-293, 2012.

[23] Z. L. Zhang, Z. L. Huang, B. Rao, T. Guan, and Z. F. Yan, “The sources of ore-forming fluid in the Huize lead-zinc ore deposits: evidences for water-rock reaction," Journal of Jilin University, vol. 35, no. 5, pp. 587-592, 2005.

[24] Z. L. Zhang, Characteristics and Sources of Ore-Forming Fluids in Huize Pb-Zn Deposit, Yunnan Province: Evidence from Fluid Inclusion and Water Rock Reaction Experiments, Institute of Geochemistry, Chinese Academy of Sciences, Guiyang, China, 2006.

[25] Z. L. Zhang, Z. L. Huang, B. Rao, T. Guan, and Z. F. Yan, "Are lead sulphides and zinc sulphides of lead-zinc ore deposits precipitated from acidicc solutions? A discussion $\mathrm{n}$ the ore-forming fluid of Huize lead-zinc ore deposit, Yunnan province," Acta Mieralogica Sinica, vol. 26, no. 1, pp. 53-58, 2006.

[26] R. S. Han, C. Q. Liu, Z. L. Huang et al., "Fluid inclusions of calcite and sources of ore-forming fluids in the Huize $\mathrm{Zn}$ $\mathrm{Pb}-(\mathrm{Ag}-\mathrm{Ge})$ district, Yunnan, China," Acta Geologica Sinica - English Edition, vol. 78, no. 2, pp. 583-591, 2004.

[27] R. S. Han, H. J. Zou, B. Hu, Y. Z. Hu, and C. D. Xue, "Features of fluid inclusions and sources of ore-forming fluid in the Maoping carbonate-hosted $\mathrm{Zn}-\mathrm{Pb}-(\mathrm{Ag}-\mathrm{Ge})$ deposit, Yunnan, China," Acta Petrologica Sinica, vol. 23, no. 9, pp. 2109-2118, 2007.

[28] C. Zhou, "The source of mineralizing metals, geochemical characterization of ore-forming solution, and metallogenetic mechanism of Qilingchang $\mathrm{Pb}-\mathrm{Zn}$ deposit, Northeastern Yun-nan province, China," Bulletin of Mineralogy, Petrology and Geochemistry, vol. 17, no. 1, pp. 34-36, 1998. 
[29] X. R. Yan, Metallogenic Model and Prediction of Huize Pb-Zn Deposit, Kunming University of Science and Technology, Kunming University of Science and Technology, Kunming, China, 2007.

[30] K. H. Zhong, W. Liao, M. Y. Song, and Y. Q. Zhang, "Discussion on sulfur isotope of Huize $\mathrm{Pb}-\mathrm{Zn}$ deposit in Yunnan, China," Journal of Chengdu University of Technology, vol. 40, no. 2, pp. 130-138, 2013.

[31] Y. Zhang, R. S. Han, X. Ding, J. J. He, and Y. R. Wang, “An experimental study on metal precipitation driven by fluid mixing: implications for genesis of carbonate-hosted lead-zinc ore deposits," Geochimica, vol. 38, no. 2, pp. 202-215, 2019.

[32] Y. Zhang, R. S. Han, X. Ding, Y.-R. Wang, and P.-T. Wei, "Experimental study on fluid migration mechanism related to $\mathrm{Pb}-\mathrm{Zn}$ super-enrichment: implications to mineralisation mechanisms of the $\mathrm{Pb}-\mathrm{Zn}$ deposits in the Sichuan-YunnanGuizhou, SW China," Ore Geology Reviews, vol. 114, no. 103110, pp. 1-19, 2019.

[33] Y. Zhang, R. S. Han, and P. T. Wei, "The order of sphalerite and galena precipitation: a case study from lead-zinc deposits in Southwest China," Journal of Central South University, vol. 27, pp. 288-310, 2020.

[34] A. B. Carpenter, M. L. Trout, and E. E. Pickett, "Preliminary report on the origin and chemical evolution of lead-and zincrich oil field brines in Central Mississippi," Economic Geology, vol. 69, no. 8, pp. 1191-1206, 1974.

[35] B. W. D. Yardley, "Metal concentrations in crustal fluids and their relationship to ore formation," Economic Geology, vol. 100, no. 4, pp. 613-632, 2005.

[36] G. K. Czamanske, E. Roedder, and F. C. Burns, "Neutron activation analysis of fluid inclusions for copper, manganese and zinc," Science, vol. 140, no. 3565, pp. 401-403, 1963.

[37] D. M. Pinckney and J. Haffty, "Content of zinc and copper in some fluid inclusions from the Cave-in-Rock District Southern Illinois," Economic Geology, vol. 65, no. 4, pp. 451-458, 1970.

[38] B. Stoffell, M. S. Appold, J. J. Wilkinson, N. A. Mcclean, and T. E. Jeffries, "Geochemistry and evolution of Mississippi Valley-type mineralizing brines from the Tri-State and Northern Arkansas districts determined by LA-ICP-MS microanalysis of fluid inclusions," Economic Geology, vol. 103, no. 7, pp. 1411-1435, 2008.

[39] J. J. Wilkinson, B. Stoffell, C. C. Wilkinson, T. E. Jeffries, and M. S. Appold, "Anomalously metal-rich fluids form hydrothermal ore deposits," Science, vol. 323, no. 5915, pp. 764$767,2009$.

[40] M. H. Reed, "Sulfide mineral precipitation from hydrothermal fluids," Reviews in Mineralogy and Geochemistry, vol. 61, no. 3, pp. 95-109, 2006.

[41] R. H. Petrucci and W. S. Harwood, General Chemistry: Principles and Modern Applications, Macmillan, 1977.

[42] D. W. Oxtoby, H. P. Gillis, and A. Campion, Principles of Modern Chemistry, Thomson Higher Education, 7th edition, 2012.

[43] J. Y. Cao, B. B. Lu, B. Ma, and S. Y. Li, "Reviews on the vlllcanization and flotation of oxidized lead-zinc ores," Multipurpose Utilization of Mineral Resources, vol. 2, pp. 17-21, 2016.

[44] D. L. Leach, D. F. Sangster, K. D. Kelley et al., "Sedimenthosted lead-zinc deposits: a global perspective," Economic Geology, vol. 100, pp. 561-607, 2005.

[45] G. M. Anderson, Some Geochemical Aspects of Sulfide Precipitation in Carbonate Rocks, G. Kisvarsanyi, S. K. Grant, W. P.
Pratt, and J. W. Koenig, Eds., International Conference of MVT Lead-Zinc Deposits, 1983, pp. 61-76, University of Missouri Rolla, Rolla, MO, USA, 1983.

[46] D. A. Sverjensky, "Genesis of Mississippi Valley-type lead-zinc desposits," Annual Review of Earth and Planetary Sciences, vol. 14, no. 1, pp. 177-199, 1986.

[47] T. J. Barrett and G. M. Anderson, "The solubility of sphalerite and galena in 1-5 m NaCl solutions to $300^{\circ} \mathrm{C}$," Geochimica et Cosmochimica Acta, vol. 52, no. 4, pp. 813-820, 1988.

[48] J. S. Hanor, "Controls on the solubilization of lead and zinc in basin brines," Society of Economic Geologists Special Publication, vol. 4, pp. 483-500, 1996.

[49] N. I. Basuki, "A review of fluid inclusion temperatures and salinities in Mississippi Valley-type $\mathrm{Zn}-\mathrm{Pb}$ deposits: identifying thresholds for metal transport," Exploration and Mining Geology, vol. 11, no. 1-4, pp. 1-17, 2002.

[50] Y. Zhang, R. Han, and P. Wei, "Research overview on the migration and precipitation mechanisms of lead and zinc in ore-forming fluid systerm for carbonate-hosted lead-zinc deposits," Geological Review, vol. 62, no. 1, pp. 187-201, 2016.

[51] C. B. Anderson, "Understanding carbonate equilibria by measuring alkalinity in experimental and natural systems," Journal of Geoscience Education, vol. 50, no. 4, pp. 389-403, 1997.

[52] T. H. Giordano and H. L. Barnes, "Ore solution chemistry VI; $\mathrm{PbS}$ solubility in bisulfide solutions to $300^{\circ} \mathrm{C}$," Economic Geology, vol. 74, no. 7, pp. 1637-1646, 1979.

[53] W. L. Bourcier and H. L. Barnes, "Ore solution chemistry: VII. Stabilities of chloride and bisulphide complexes of zinc to 350 C," Economic Geology, vol. 82, no. 7, pp. 1839-1863, 1987.

[54] N. N. Akinfiev and B. R. Tagirov, "Zn in hydrothermal systems: thermodynamic description of hydroxide, chloride, and hydrosulfide complexes," Geochemistry International, vol. 52, no. 3, pp. 197-214, 2014.

[55] R. Zhong, J. Brugger, Y. Chen, and W. Li, "Contrasting regimes of $\mathrm{Cu}, \mathrm{Zn}$ and $\mathrm{Pb}$ transport in ore-forming hydrothermal fluids," Chemical Geology, vol. 395, pp. 154-164, 2015.

[56] W. L. Bourcier and H. L. Barnes, "Ore solution chemistry; VII, Stabilities of chloride and bisulfide complexes of zinc to $350^{\circ}$ C," Economic Geology, vol. 82, no. 7, pp. 1839-1863, 1987.

[57] Y. Zhang, Fluid Mixing Metallogenic Mechanism of Huize Super-Large Lead-Zinc Deposits in Northeast of Yunnan Poly-metallic Mineralization Domain, Kunming University of Science and Technology, Kunming, China, 2016. 